\title{
Dynamic Response Characteristics of a Toppling Rock Slope Under Seismic Excitation using Time- frequency Joint Analysis Method: A Case Study from the Southwest of Sichuan Basin, China
}

\author{
Danqing Song \\ Tsinghua University \\ zhuo chen (D 13882535009@163.com) \\ Sichuan University \\ Lihu Dong \\ Shenyang University of Technology \\ Han Du \\ Tsinghua University
}

\section{Research Article}

Keywords: Seismic response characteristic , time-frequency analysis, toppling slope, weak structural plane, earthquake

Posted Date: March 18th, 2021

DOI: https://doi.org/10.21203/rs.3.rs-312678/v1

License: (a) (i) This work is licensed under a Creative Commons Attribution 4.0 International License.

Read Full License 

using time-frequency joint analysis method: a case study from the southwest of Sichuan Basin, China Danqing Song ${ }^{1}$, Zhuo Chen ${ }^{2,3 *}$, Lihu Dong ${ }^{4}$, Han $\mathrm{Du}^{1}$ 1. State Key laboratory of Hydroscience and Engineering, Tsinghua University, Beijing, 100084, China 2. Faculty of Geosciences and Environmental Engineering, Southwest Jiaotong University, Chengdu, 611756, China 3. State Key Laboratory of Hydraulic and Mountain River Engineering, Department of Geotechnical Engineering, Sichuan University, Chengdu, 610065, China 4. School of Electrical Engineering, Shenyang University of Technology, Shenyang, 110870, China *Corresponding author. Tel.: +86 15102830216. E-mail address: 13882535009@163.com (Z. Chen)

\section{Abstract}

The two-dimensional dynamic analysis was used to study the dynamic response characteristics of a toppling rock slope based on the time-frequency joint analysis method using the FLAC (Fast Lagrangian Analysis of Continua). Two-dimensional dynamic analyses were carried out on two numerical models. The results of the numerical dynamic analyses show that the toppling slope has an topographic and geological dynamic amplification effect. There are an elevation and surface dynamic amplification effect in the toppling slope. The impacts of the structural planes in the models on their wave propagation characteristics and magnification effect were discussed. Directions of ground motion have impacts on the dynamic response of the models. Based on the frequency-domain analysis, the relationship between the frequency of waves and the dynamic response of the models was further 
studied. The geological structure have a great effect on the high-frequency components of waves. The analyses of marginal spectrum show that the energy mainly concentrated in the frequency band of seismic wave $(7-10 \mathrm{~Hz})$. Moreover, the seismic failure mechanism of the toppling rock slope was discussed. Geological structure determines the seismic failure mode of the slope. Cracks initiate in the top toppling plane, and the surface slope is damaged firstly under earthquake excitation; with the increase of seismic loading, a large-scale slip mass further forms gradually from the upper to the lower slope body.

Key words: Seismic response characteristic $\cdot$ time-frequency analysis $\cdot$ toppling slope $\cdot$ weak structural plane $\cdot$ earthquake

\section{Introduction}

The landform of western China is mainly mountainous, and earthquakes have induced a mass of landslides (Liu et al. 2014; Zhou et al. 2017; Chen et al. 2020). Field investigation after the 2008 Wenchuan earthquake shows that seismic wave propagation in rock-soil body weakens the stability of slopes to a large extent (Yin et al. 2015). Post-earthquake investigation also suggests that the movement direction of the landslides was closely related to the movement direction of the fault, indicating that the waves propagation direction had closely related to the landslide movement (Xu et al. 2012). The spatial distribution rule of earthquake-induced landslides after the earthquake also reveals that seismic landslides have certain topographic and geological amplification effects (Wang et al. 2010; Huang et al. 2012). On June 24, 2017, the Xinmo village landslide occurred in Sichuan province, China. The massive landslide is affected by several previous strong earthquakes in history in China, such as the 1933 Diexi earthquake, 2008 Wenchuan earthquake and 2013 Lushan earthquake (Fan et al. 2017b; 
Chen and $\mathrm{Wu}$ 2018). The influence of earthquakes on the stability of landslides has attracted the attention of many scholars.

With the long-term geological action, there will be many discontinuous joints in the rock mass, and even forms penetrating structural planes to cut the rock mass into discontinuous bodies (Song et al. 2018c; Wu et al. 2014). The discontinuous geological structure in the rock mass weakens its strength and stability. Moreover, the failure modes of toppling rock slopes containing discontinuities mainly include the following: bend toppling, block toppling, and massive bending and toppling (Goodman and Bray 1976; Alejano et al. 2010). The dynamic failure modes of rock slopes are affected by discontinuities distribution (Zhou et al. 2017; Song et al. 2019). Due to the randomness of earthquake and the complexity of rock mass structural materials, the stability of rock slope is difficult to be fully understood. Hence, the dynamic stability of rock slope needs to be further studied.

Time domain analysis is the analysis method of dynamic response of slopes, in which the dynamic acceleration response is the analysis parameter (Fan et al. 2017a; Li et al. 2018; Song et al. 2018a,b). At present, the acceleration response is used to study the dynamic response characteristics of various types of slope, such as jointed slope (Li et al. 2018), rock slopes with weak structural surface (Song et al. 2018a,b), and layered slopes (Fan et al. 2016). In addition, frequency-domain analysis can well explore the relationship between seismic wave frequency, natural frequency and dynamic response characteristics of slopes (Song et al. 2019). Moore and Gischig (2011) studied the dynamic response law of slopes by using the Fourier spectrum response of the large rock slope. Li et al. (2019) investigated the dynamic response of jointed slopes and the damage characteristics in the slope by analyzing the Fourier spectrum. He et al. (2020) investigated the seismic stability of a landslide by analyzing the Fourier spectrum response of the strong earthquake seismograph array. The slope 
instability caused by the resonance between the excellent frequency of waves and the natural frequency of slopes has always been a hot issue in the field of seismic engineering. Moreover, Yang et al. (2015) used HHT to study the dynamic response of a rock landslide and the triggering mechanism of landslide from the perspective of energy, which showed that time-frequency domain analysis could better reflect the dynamic response law of slope. Fan et al. (2016, 2017a) used HHT and marginal spectrum to study the seismic failure mode of the bedding rock slopes, which showed that the change of marginal spectrum peak value could better reflect the seismic failure development process in the slope. However, the seismic wave is a typical random wave, which is rich in more complex frequency components. Moreover, due to the heterogeneity and nonlinearity characteristics of rock mass, the dynamic response characteristics of rock mass are difficult to be fully understood. It is should further clarify the dynamic characteristics of slopes from the perspective of frequency domain. In addition, since the time-frequency-amplitude characteristics of seismic waves, it is necessary to further reveal the seismic response of slopes in the time-frequency domain. The previous research on the seismic response of rock slopes focuses on time-domain analysis, but ignores the frequency domain and time-frequency domain analysis. Therefore, in order to solve the above problems, it is necessary to establish a time-frequency joint analysis method to systematically reveal the seismic response characteristics of complex rock slopes.

A time-frequency joint analysis method is proposed to study the seismic response law of a toppling slope, as shown in Fig. 1. Two-dimensional dynamic analyses are performed on two numerical models using FLAC3D. This work focuses on research three aspects in this research, including acceleration response (time-domain analysis), modal analysis and Fourier spectrum analysis (frequency-domain analysis), and marginal spectral analysis of the models (time-frequency domain analysis). The 
influence of topographic and geological conditions on the seismic response of the models were analysed. In addition, this work also analyze the relationship between the natural frequencies and dynamic characteristics of slopes. The dynamic failure mechanism of the toppling slope is discussed as well.

\section{Numerical model and dynamic analyses}

\subsection{Case study}

The rock slope is located in the hilly region of Sichuan Province in western China, where the river system, gullies and valleys are developed. The landform in the region is dominated by mountains, hills and valley plains (Fig. 2). The elevation of the slope is between $435-540 \mathrm{~m}$. The strata in the slope area are continuous, with gentle occurrence and no fault passing through. Under the influence of regional tectonic stress, dead weight stress and unloading, rock joints in the area are very developed. The research area is at the western edge of the Yangtze quasi platform in western China. The regional geological structure is mainly manifested as a series of fold and compressional fault in NNE. In the northwest of the slope area is the Longmen mountain front fault zone, and in the southwest of the area is Xianshuihe-Anning river fault zone, both of which belong to large regional seismogenic fault tectonic zones with a distance of more than $80 \mathrm{~km}$ from the slope. Three small seismic fault zones are distributed near the slope.

The slope with weak structural plane is about $70 \mathrm{~m}$ long, $76 \mathrm{~m}$ high with a gradient of $30^{\circ}$. The micro-geomorphology of slope is steep slope-gentle slope, and the upper platform of slope is developed. The interbedded silty mudstone and argillaceous silty siltstone $\left(\mathrm{K}_{\mathrm{lg} 1}{ }^{1-3}, \mathrm{~K}_{\mathrm{lg} 1}{ }^{1-2}\right)$ of the quaternary residual silty clay $\left(\mathrm{Q}^{\mathrm{el}+\mathrm{dl}}\right)$ and the third and second lithologic members of the Guankou 
111 Formation of Lower Cretaceous are mainly exposed on the slope. The development of slope has

112

113

multilayer weak bedding structural planes, joints and fissures. The weak structural plane is developed on the contact surface between argillaceous silty sandstone and silty mudstone. The weak structural plane is distributed in a zonal continuous manner on the slope with a thickness of $3-30 \mathrm{~cm}$. Laboratory tests were performed to obtain the mechanical parameters of the slope (Table 1). According to the geological structure type of the slopes, the geological model of the toppling slope is simplified as shown in Fig. $3 b$.

\subsection{Numerical model}

The rock mass of the model is elastoplastic material, and the Mohr-coulomb strength criterion is adopted. The calculated boundary of the model is as follows: the length from the foot of the slope to the right boundary is twice the length of the slope, the length from the top of the slope to the left boundary is twice the height of the slope, and the height from the top to the bottom of the slope is twice the height of the slope. The boundary range meets the requirements of calculation accuracy under static and dynamic conditions (Xu et al. 2008). Model 1 (homogeneous slope) and Model 2 (toppling slope) were established, and the two numerical mesh models are shown in Fig. 4, whose size is $80 \times 170 \mathrm{~m}$. To reduce the difficulty of simulation, the structural planes were simplified into a weak band with the depth of $0.2 \mathrm{~m}$. A quadrilateral grid with a side length of $0.5 \mathrm{~m}$ was used to investigate the characteristics of the model. The model consists of 30,729 surface strain elements and 32,202 mesh nodes. FLAC is used as solver for dynamic analysis using its transient dynamics simulation capability. The damping in dynamic analysis module includes Rayleigh damping, local damping and viscous 
132

133

damping. Local damping converges by changing the mass of nodes or structural elements in the vibration period. Local damping is used in the model.

In dynamic analysis, model boundary processing is a key technology. Improper boundary will lead to wave reflection and refraction, which will seriously affect the result of dynamic analysis. Apparently, the amplitude of seismic wave propagating in the model is closely related to frequency, structural plane type and thickness (Langston et al. 2009). In the finite element numerical calculation, it is one of the common methods to use the model with linear elasticity or complex dissipation characteristics to simulate the structural plane. In this model, the discontinuity is simulated as a soft material rigidly connected with the rock mass, and the selection of the thickness of the discontinuity is more critical. The range of the discontinuity should be greater than the wavelength, and the thickness should be less than the wavelength.

For the dynamic response analysis of a semi-infinite space body such as a slope, the boundary problem which actually tends to infinity must be dealt with. FLAC provides static boundary (viscous boundary) and free field boundary in the numerical simulation calculation,. The research object in this work is a rock slope, whose foundation modulus is large and can be considered as a rigid foundation. Therefore, static boundary conditions are not required at the bottom of the model. The free field boundary is set around the model, so that the side boundary of the main grid is coupled with the free field grid through dampers. The unbalanced force of the free field grid is applied to the boundary of the main grid. Since the free field boundary provides the same effect as the infinite field, the upward surface wave will not distort. The boundary conditions are set as shown in Fig. 3b. In order to study the dynamic response of the slope, some monitoring points are set up in the model. The rock mass is elastoplastic material, and the Mohr-coulomb strength criterion is adopted. The boundary is free field boundary and local 
154

155

156

157

158

159

160

162

163

164

165

166

167

168

169

170

171

172

173

174

175

damping is adopted. The damping coefficient is 0.156 . Static calculation was performed before dynamic calculation (Zheng et al. 2002). In order to eliminate the adverse effect of the dead weight of the slope, stress balance should be carried out before the numerical simulation.

Two loading directions of Wenchuan Earthquake waves (the $z$ and $x$ directions) were applied at the bottom boundary of the model, and the corresponding time history curve and Fourier spectrum are shown in Fig. 5. The Wenchuan Earthquake (WE) records were recorded at Wudu in Gansu of China. The dominant frequency wave is $7.74 \mathrm{~Hz}, t=120 \mathrm{sec}$ and $\Delta t=0.005 \mathrm{sec}$ to create time-dependent acceleration inputs at the bottom of the slope during horizontal and vertical motions in the dynamic calculations.

\section{Analysis of time domain}

To analyze the influence of weak structural plane on the wave propagation characteristics, taking the input WE wave $(0.1 \mathrm{~g})$ in $x$ direction as examples, the acceleration distribution of slope at different times was extracted. The acceleration distribution of the two models are shown in Fig. 6. It can be found that waves mainly propagate along the slope surface from the bottom to the top of the slopes. By comparing Figs. $6 \mathrm{a}$ and $6 \mathrm{~b}$, the acceleration distribution characteristics of the toppling rock slope have obvious changes. An obvious change phase difference can be found on both sides of the weak planes. The local magnification amplification effect of the toppling slope can be identified, which indicates that the weak structural plane affected the propagation characteristics of seismic waves inside the slope. This is because the existence of weak structural plane causes refraction and reflection effects of seismic waves when wave propagates in the rock mass, so that seismic wave appears superposition near the weak planes, and further results in an local amplification effect of waves. 
176

Acceleration time history is the core parameter to investigate the seismic response of slopes in the time domain (Fan et al. 2016, 2017a). The PGA (peak ground acceleration) reflects the strongest response in the whole acceleration time-history and reflects the maximum seismic inertial force at a certain position in the slope. The $\mathrm{M}_{\mathrm{PGA}}$ is used to analyze the acceleration response of slopes. $\mathrm{M}_{\mathrm{PGA}}$ is introduced to define the ratio of PGA at any point in the slope and PGA at the slope toe (point A1) as $\mathrm{M}_{\mathrm{PGA}}$, which represents acceleration magnification at a point of the slope. Four typical monitoring points (A1, A3, 15 and A7) of the slope surface are selected, and their acceleration-time histories and Fourier spectra curves are shown in Figs. 7 and 8 . The changes of $\mathrm{M}_{\mathrm{PGA}}$ of the two models with relative elevation are shown in Fig. 9. The relative elevation $(h / H)$ refers to the ratio of height of one point to the height $(H)$ of the model. The $h$ refers to the height from the bottom of the slope. Fig. 9a shows that the $\mathrm{M}_{\mathrm{PGA}}$ of the Model 1 increases with the relative elevation, and reaches the maximum at the top of the slope. The $\mathrm{M}_{\mathrm{PGA} \text { max }}$ are approximate 1.2 and 1.14, when input seismic waves in $x$ - and $z$-directions, respectively. This shows that the acceleration amplification effect of the slope increases with the elevation, and the slope owns an elevation amplification effect. The $\mathrm{M}_{\mathrm{PGA}}$ of the toppling slope increases with the elevation as well, indicating that the slope also has a typical elevation amplification effect (Fig. 9b). However, compared Figs. 9a and 9b, the $\mathrm{M}_{\mathrm{PGA}}$ of the homogeneous slope shows a linear increasing trend with elevation, overall, while the toppling slope shows a significant nonlinear increase, indicating that the weak structural plane has influence on the dynamic magnification effect of the model. This is because weak structural planes cause the discontinuity of rock mass, and the refraction and reflection effects of waves appear near the weak structural plane, which leads to the nonlinear variation characteristics of amplification effect. It can be found that $\mathrm{M}_{\mathrm{PGA}}$ at the slope surface is significantly larger than that inside the slope, suggesting that the slope has a significant amplification 
198

effect on the surface. Moreover, the $\mathrm{M}_{\mathrm{PGA}}$ of the toppling slope is approximate 1.1 times that of the homogeneous slope, which indicates that the weak structural plane has a certain amplification effect on the slope. In addition, in the homogeneous slope (Fig. 9a), the MPGAmax under horizontal seismic force is about 1.05 times that under vertical seismic force, while in the reverse slope (Fig. 9b), the $\mathrm{M}_{\mathrm{PGA} \text { max }}$ when input seismic waves in $x$-direction is about 1.15 times when input seismic waves in $z$-direction. This indicates that the directions of seismic excitation have effect on the dynamic response of the slope in a large degree, and the acceleration amplification effect under horizontal earthquake excitation is greater.

In addition, it can be seen from Figure 10 that the acceleration amplification factor obtained from the model test is similar to the numerical simulation result (Fan 2016), which indicates that the numerical calculation result is reliable. It is worth noting that, in the numerical calculation, the size and physical and mechanical parameters of the rock mass model are the same as those of the original slope, but in the shaking table test, the physical and mechanical parameters of the model are calculated according to the similarity ratio. The experimental model is a scale model, which has a certain size effect compared with the original slope. During the construction of the test model, there are some differences in the adhesion between the simulated rock mass and the structural plane, which is different from the original slope. These factors directly lead to the difference between the numerical results and the shaking table test results. But in general, the numerical results and experimental results can better reflect the dynamic response law of the slope, and the analysis results of both confirm each other.

\section{Analysis of frequency-time domain}


4.1 Principle of the frequency-time domain analysis

The frequency-domain analysis mainly includes the modal analysis, and the Fourier spectrum analysis using FFT. The principles of FFT and modal analysis are as follows.

Modal analysis has become a basic type of dynamic frequency-domain analysis (Song et al. 2019). It can reveal the natural frequency and vibration mode of slopes, and also predict the dynamic response of slopes in elastic domain by using modal analysis. The dynamic control equation of the modal analysis is as follows (Reale et al. 2016): $[M]\{U+[K]\{U\}=0$. Where $\{U\}$ and $\{\ddot{U}\}$ are the displacement and acceleration vectors, respectively. $[\dot{M}]$ and $[K]$ are the mass matrix and stiffness matrix of the model, respectively. The corresponding characteristic equation is as follows: $\left([M \&]-\omega_{i}^{2}[M]\right)\{U\}=0$. Where the $\omega_{i}$ is the $i$-th natural circular frequency. Then the natural frequency $f_{i}$ is as follows: $f_{i}=\frac{\omega_{i}}{2 \pi}$. The eigenvector corresponding to the eigenvalue is $\{U\}_{i}$, which represents the vibration mode at the natural frequency $f_{i}$. It is worth noting that the low order vibration mode has a control effect on the dynamic characteristics of the engineering body. Therefore, in modal analysis, only the first few modes and modes are considered. In addition, FFT is used to analyze the vibration response of rock and soil mass, which can clearly identify different frequency components of signals. FFT can quickly identify the main components of the signal, and can also be quickly filtered, etc., which has become a common method to deal with seismic wave signals. The mathematical expression for FFT is as follows (Ahmed and Rao 1975): $F(a)=\int_{-\infty}^{+\infty} x(t) e^{-j 2 \pi a t} d t$. Where the $a(t)$ is the acceleration-time history.

\subsection{Dynamic response characteristics}

The modal analysis results of the models are shown in Figs. 11-13. As can be seen from Fig. 11, the 
natural frequencies $(f)$ of the slopes increase with the order. The first four $f$ of the Model 1 are 2.96, 7.84, 11.18 and $18.06 \mathrm{~Hz}$, respectively. The corresponding $f$ of the toppling slope are $2.81,7.34,10.69$ and $17.63 \mathrm{~Hz}$, respectively. The natural frequency of the Model 2 is less than that of the Model 1. This is due to that the toppling slope contains multiple structural planes, which decreases the stiffness of the rock mass. This suggests that the structural plane affects the natural frequency of the models to a certain extent. In Figs. 12 and 13, the $U$ refers the relative displacement of the models under certain a mode of vibration. Figs. 12 and 13 show that the first four modes of the Model 1 are similar to the Model 2 as a whole. However, the $U$ near the structural surface of the Model 2 has a discontinuous distribution, with a certain phase shift, which indicates that the structural plane affects the dynamic response of rock mass. Figs. 12 and 13 show that the $U_{\max }$ of the Model 2 is larger than that of the Model 1 at the same order, in particular, the higher order modal characteristics of the slopes are different. This is because the slope deformation are enlarged by weak surfaces. The modal characteristics of different orders show that the $U$ of the slope increases with the slope height on the whole, suggesting that the slopes have an obvious elevation amplification effect, and initiate to damage on the slope crest. Moreover, Figs. 12 and 13 also show that under the same elevation condition, the $U$ of the slope surface is significantly larger than that inside the slope body, which is similar with the time-domain results.

In addition, the dynamic response of the slope is further analysed by using Fourier spectrum analysis.

Fig. 7 shows that the homogeneous slope is composed of three predominant frequencies $\left(f_{1}-f_{3}\right)$ and the toppling slope owns four predominant frequencies $\left(f_{1-} f_{4}\right)$. The values of the predominant frequencies are similar with the modal analysis. Fourier spectrum analysis and modal analysis further determined the $f$ of the slopes. Comparing the Fourier spectrum of the slopes, the toppling slope has $f_{4}$, which 
indicates that structural planes has an obvious magnification effect on the high-frequency components of waves. Figs. 14 and 15 show that the PFSA of the slopes increases with the elevation at different natural frequencies, and compared with the the PFSA of internal slope body, the slope surface is significantly larger, indicating that the slope has obvious elevation and slope surface magnification effect, which is consistent with the analysis results in the time domain. Moreover, it can be found that the PFSA of the Model 2 is approximately 1.3 times that of the Model 1 . The PFSA of the $f_{1}$ and $f_{2}$ shows a linear increasing trend, while that of $f_{3}$ and $f_{4}$ shows a nonlinear increasing trend on the whole, suggesting that structural plane affects on the high-frequency components of waves in a large degree. Therefore, modal analysis and Fourier spectrum analysis can clearly identify the relationship between the frequency components of waves and the amplification effect of the slopes.

\section{Analysis of time-frequency domain}

5.1 Principle of the time-frequency domain analysis

HHT method that is proposed to process non-stationary signal (Huang et al. 1998). HHT method is mainly composed of empirical mode decomposition (EMD) method and Hilbert spectrum analysis (HSA), which provides a feasible tool for identifying earthquake Hilbert energy distribution (Fan et al. 2017a). By using the EMD, the seismic wave is decomposed into a series of intrinsic mode functions (IMFs). The flowchart for EMD approach is shown in Fig. 16 (Zhang 2006). The Hilbert spectrum is as follows: $H(\omega, t)=\operatorname{Re} \sum_{j=1}^{n} a_{j}(t) e^{i \int \omega_{j}(t) d t}$. HHT marginal spectrum is defined as the integral of Hilbert Huang spectrum on the time axis, whch is as follows: $h(\omega)=\int_{0}^{T} H(\omega, t) d t$. The marginal spectrum can show the accumulation of IMF amplitude in the whole period. Every instantaneous frequency has a certain amount of energy. By accumulating the energy of these instantaneous 
frequencies, the total energy corresponding to the frequency in the original signal can be calculated, that is, the marginal spectrum amplitude (MSA).

\subsection{Dynamic response characteristics}

The marginal spectrum shows the energy distribution of the slope vibration, and the instantaneous spectrum can reflect the time-varying characteristics of the seismic wave signal. By analyzing the variation of marginal spectral amplitude, the propagation characteristics of seismic energy can be determined. Taking the acceleration time history of point A1 in the toppling slope an example, the first four IMFs and instantaneous frequency are obtained by EMD, as shown in Fig. 17. Then, the marginal spectrum of the IMFs can be obtained by using HHT. As can be seen from Fig. 17, the amplitude of IMF2 is larger, and its frequency component is much richer, which is easier to identify. So we use IMF2 to get the marginal spectrum. The edge spectrum of typical measurement points in model 2 is shown in Fig. 18. The peak of marginal spectrum amplitude (PMSA) is mainly located in the range of 7-10 Hz. This frequency band is similar to $f_{2}$ and $f_{3}$ of the Model 2, so the seismic wave energy in this frequency band is more suitable for analyzing the dynamic response characteristics of slope.

In addition, the PMSA of the homogeneous and toppling slopes with the elevation are shown in Fig. 19. The PMSA of the slopes increases with the increase of elevation, and the PMSA of the slope surface is larger than that of the internal slope. This phenomenon indicates that the slope surface and elevation magnify the energy propagation of seismic wave in a certain degree. Moreover, Fig. 19 shows that the PMSA $z$ when input wave in $z$-direction is significantly less than the PMSAx under horizontal seismic loading. The PMSAx is about 1.1 times that of PMSA $z$ in the homogeneous slope, and the PMSAx of the toppling slope is approximately 1.15 times that of PMSAz. This indicates that the direction of iput 
wave has influence on the energy propagation of seismic wave, and the geological amplification effect when input wave in $x$-direction is larger. It can be also found that the PMSA of the toppling slope is about 1.2 times that of the homogeneous slope. This shows that the structural plane magnifies the propagation energy of seismic wave in rock mass. Therefore, the dynamic response of the slopes can be investigated from the energy-based perspective in the time-frequency domain.

\section{Analysis of dynamic failure mechanism of the slopes}

Taking the input in WE wave $(0.1 \mathrm{~g})$ in $x$ direction as an example, the stress distribution of the toppling slope is shown in Fig. 20. Fig. 20 shows that the maximum stress occurs in the surface slope. This phenomenon suggest that the surface slope initiates to damage under excitation area, and the topmost structural plane are the potential slip surface. The contour of shear strain increment of the slope under different ground motion intensity is shown in Fig. 21. It can be found that the shear strain increment in the rock is much smaller than that in the structural planes, which suggests that the structural planes are the potential slip surfaces.

The time-frequency joint analysis shows that the initiation and failure evolution processes of the toppling landslide can be summarized as follows: When the ground motion intensity is $0.1 \mathrm{~g}$, the shear strain increment of the topmost structural surface is relatively large, with shear failure first develops at the slope crest (Fig. 21a). Then, when it is $0.3 \mathrm{~g}$, larger shear strain increments can be observed in the topmost structural plane (Fig. 21b). With the seismic intensity increasing to 0.4 and $0.6 \mathrm{~g}$, the shear strain increment continues to expand in the lower structural planes, indicating that the damage area of the slope extends to the lower part of the slope. This analysis results of the damage process of the slope are consistent with the results of the shaking table test (Fig. 22) (Fan et al. 2016). Therefore, the 
bedding planes have a great impact on damage mechanism of the landslide, which are the potential sliding surfaces. Crack first appear in the topmost structural plane that is the primary slip surface; With the increase of ground motion intensity, the slip surface extends from the upper to the lower structural planes.

\section{Conclusions}

The numerical dynamic analysis method is used to study the dynamic response of the toppling slope.

Time-domain analysis can directly and preliminarily reflect the dynamic response characteristics of slope. Frequency-domain analysis can clarify the relationship between wave frequency component and slope dynamic response. Time-frequency analysis can reveal the dynamic response of slope from an energy-based perspective. The following conclusions can be drawn.

1. The results of time-frequency joint analysis show that the toppling slope has an obvious topographic and geological dynamic amplification effect. The dynamic amplification effect increases with the increase of elevation, and the magnification effect of slope surface is larger than that of inside slope. The structural planes have an impact on the wave propagation characteristics and amplification effect of the slope. Local amplification effect can be identified the slope, due to the refraction and reflection effect of the wave near the structural planes. The amplification effect of the slope is increased due to the distribution of structural planes. The $\mathrm{M}_{\mathrm{PGA}}$, PFSA and PMSA of the toppling slope are approximately 1.1, 1.3 and 1.2 times that of the homogeneous slope. Wave propagation directions have an impact on the dynamic response of the slope. The $\mathrm{M}_{\mathrm{PGA} \text { max }}$ under horizontal seismic loading is approximately 1.15 times that under vertical seismic loading.

2. According to the frequency-domain analysis, natural frequency has an impact on the dynamic 
352

353

354

355

356

357

358

359

360

361

362

363

364

365

response of the slope by using the Fourier spectrum and modal analysis. Structural planes have an impact on the dynamic deformation characteristics of the slope, which have an amplification effect on the high-frequency components of waves. The natural frequencies of the toppling slope is smaller than that of the homogeneous slope. The first four natural frequencies of the toppling slope are $2.81 \mathrm{~Hz}$, 7.34 Hz, $10.69 \mathrm{~Hz}$ and $17.63 \mathrm{~Hz}$, respectively.

3. According to the time-frequency joint analysis, stress distribution and contour of shear strain increment of the slope, weak structural planes are the potential slip surfaces, and have a controlling effect on the seismic failure mechanism of the toppling slope. Under continuous earthquake excitation, cracks initiate in the topmost structural plane, and the surface slope is prone to damage, which is the primary slip mass; with the increase of seismic loading, the slip surface extends from the upper to the lower structural planes, with a large-scale slip mass being further formed gradually.

\section{Acknowledgments}

This study was supported by the China Postdoctoral Science Foundation (2020M680583), National Postdoctoral Program for Innovative Talent of China (BX20200191), and the Shuimu Tsinghua Scholar Program (2019SM058).

\section{Compliance with ethical standards}

Conflict of interest The authors declare that they have no conflict of interest.

\section{References}

Ahmed N, Rao KR (1975) Fast Fourier Transform. In: Orthogonal Transforms for Digital Signal 
Processing. Springer, Berlin, Heidelberg.

Alejano LR, Gómez-Márquez I, Martínez-Alegría R (2010) Analysis of a complex toppling-circular slope failure. Eng. Geol. 114(1-2):93-104.

Chen KT, Wu JH (2018) Simulating the failure process of the xinmo landslide using discontinuous deformation analysis. Eng. Geol. 239, 269-281.

Chen Z, Song D, Hu C, Ke Y, (2020) The September 16, 2017, Linjiabang landslide in Wanyuan County, China: preliminary investigation and emergency mitigation. Landslides 17:191-204.

Fan G (2016) The dynamic response and time-frequency method for seismic stability evaluation of layered rock slope with weak intercalated layer. $\mathrm{PhD}$ thesis, Southwest Jiaotong University, Chengdu, China (In Chinese).

Fan G, Zhang J, Wu J, Yan K (2016) Dynamic response and dynamic failure mode of a weak intercalated rock slope using a shaking table. Rock Mech. Rock Eng. 49:3243-3256.

Fan G, Zhang LM, Zhang JJ, Ouyang F (2017a) Energy-Based Analysis of Mechanisms of Earthquake-Induced Landslide Using Hilbert-Huang Transform and Marginal Spectrum. Rock Mech. Rock Eng. 50:2425-2441.

Fan X, Qiang X, Scaringi G, Dai L, Li W, Dong X, Zhu X, Pei X, Dai K, Havenith HB (2017b) Failure mechanism and kinematics of the deadly june 24th 2017 xinmo landslide, maoxian, sichuan, china. Landslides 14(6):2129-2146.

Goodman RE, Bray JW (1976) Toppling of rock slopes. In Proc. Speciality Conference on Rock Engineering for Foundation and Slopes (pp. 201-234). ASCE.

He J, Qi S, Wang Y, Saroglou C (2020) Seismic response of the Lengzhuguan slope caused by topographic and geological effects. Eng. Geol. 265:105431. 
Huang MW, Chen CY, Wu TH, Chang CL, Liu SY, Kao CY (2012) GIS-based evaluation on the fault motion-induced coseismic landslides. J. Mt. Sci. 9:601-612.

Huang NE, Shen Z, Long SR, Wu MC, Shih HH, Zheng Q, Yen NC, Tung CC, Liu HH (1998) The empirical mode decomposition and the Hilbert spectrum for nonlinear and non-stationary time series analysis. Proc. R. Soc. London. Ser. A Math. Phys. Eng. Sci. 454:903-995.

Langston CA, Lee WHK, Lin CJ, Liu CC (2009) Seismic-wave strain, rotation, and gradiometry for the 4 march 2008 taiger explosions. B Seismol Soc Am 99(2B):1287-1301.

Li HH, Lin CH, Zu W, Chen CC, Weng MC (2018) Dynamic response of a dip slope with multi-slip planes revealed by shaking table tests. Landslides 15:1731-1743.

Li LQ, Ju NP, Zhang S, Deng XX, Sheng D (2019) Seismic wave propagation characteristic and its effects on the failure of steep jointed toppling rock slope. Landslides 16(1):105-123.

Liu HX, Xu Q, Li YR (2014) Effect of lithology and structure on seismic response of steep slope in a shaking table test. J. Mt. Sci. 11(2):371-383.

Moore JR, Gischig V (2011) Site Effects in Unstable Rock Slopes: Dynamic Behavior of the Randa Instability (Switzerland). B Seismol Soc Am 101(6):3110-3116.

Reale C, Gavin K, Prendergast LJ, Xue J (2016) Multi-modal reliability analysis of slope stability. Transportation research procedia 14: 2468-2476.

Song D, Che A, Chen Z, Ge X (2018a) Seismic stability of a rock slope with discontinuities under rapid water drawdown and earthquakes in large-scale shaking table tests. Eng. Geol. 245:153-168.

Song D, Che A, Zhu R, Ge X (2018b) Dynamic response characteristics of a rock slope with discontinuous joints under the combined action of earthquakes and rapid water drawdown. Landslides $15: 1109-1125$. 
418

Song D, Chen J, Cai J (2018c) Deformation monitoring of rock slope with weak bedding structural plane subject to tunnel excavation. Arab. J. Geosci. 11(11):251.

Wang X, Nie G, Wang D (2010) Relationships between ground motion parameters and landslides induced by Wenchuan earthquake. Earthq. Sci. 23:233-242.

Wu W, Li JC, Zhao J (2014) Role of filling materials in a P-wave interaction with a rock fracture. Eng. Geol. 172(8):77-84.

Xu C, Xu X, Dai F, Saraf AK (2012) Comparison of different models for susceptibility mapping of earthquake triggered landslides related with the 2008 Wenchuan earthquake in China. Comput. Geosci. 46:317-329.

Xu G, Yao L, Li Z, Gao Z (2008) Dynamic response of slopes under earthquakes and influence of ground motion parameters. Chinese Journal of Geotechnical Engineering 30(6):918-923.

Yang C, Zhang J, Bi J (2015) Application of Hilbert-Huang Transform to the analysis of the landslides triggered by the Wenchuan earthquake. J. Mt. Sci. 12:711-720.

Yin Y, Li B, Wang W (2015) Dynamic analysis of the stabilized Wangjiayan landslide in the Wenchuan Ms 8.0 earthquake and aftershocks. Landslides 12:537-547.

Zhang YP (2006) HHT analysis of blasting vibration and its application. PhD thesis, Central South University, Changsha, China. (In Chinese).

Zheng Y, Zhao S, Zhang L (2002) Slope stability analysis by strength reduction FEM. Engineering Science 4(10): 57-62. 

by weak structural surface. Geosci. J. 21:453-467. 


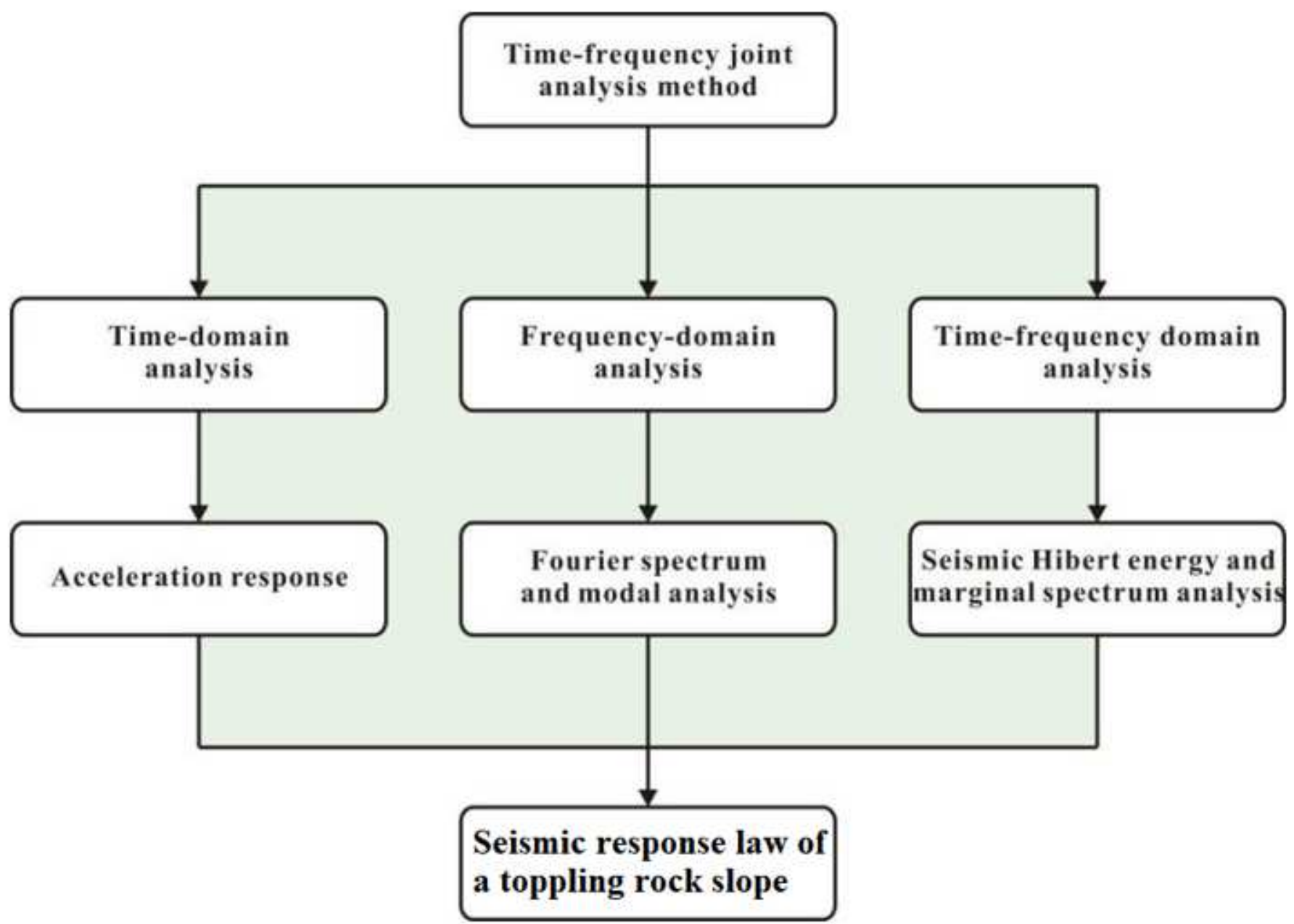

Figure 1

Flowchart for time-frequency joint analysis method. 


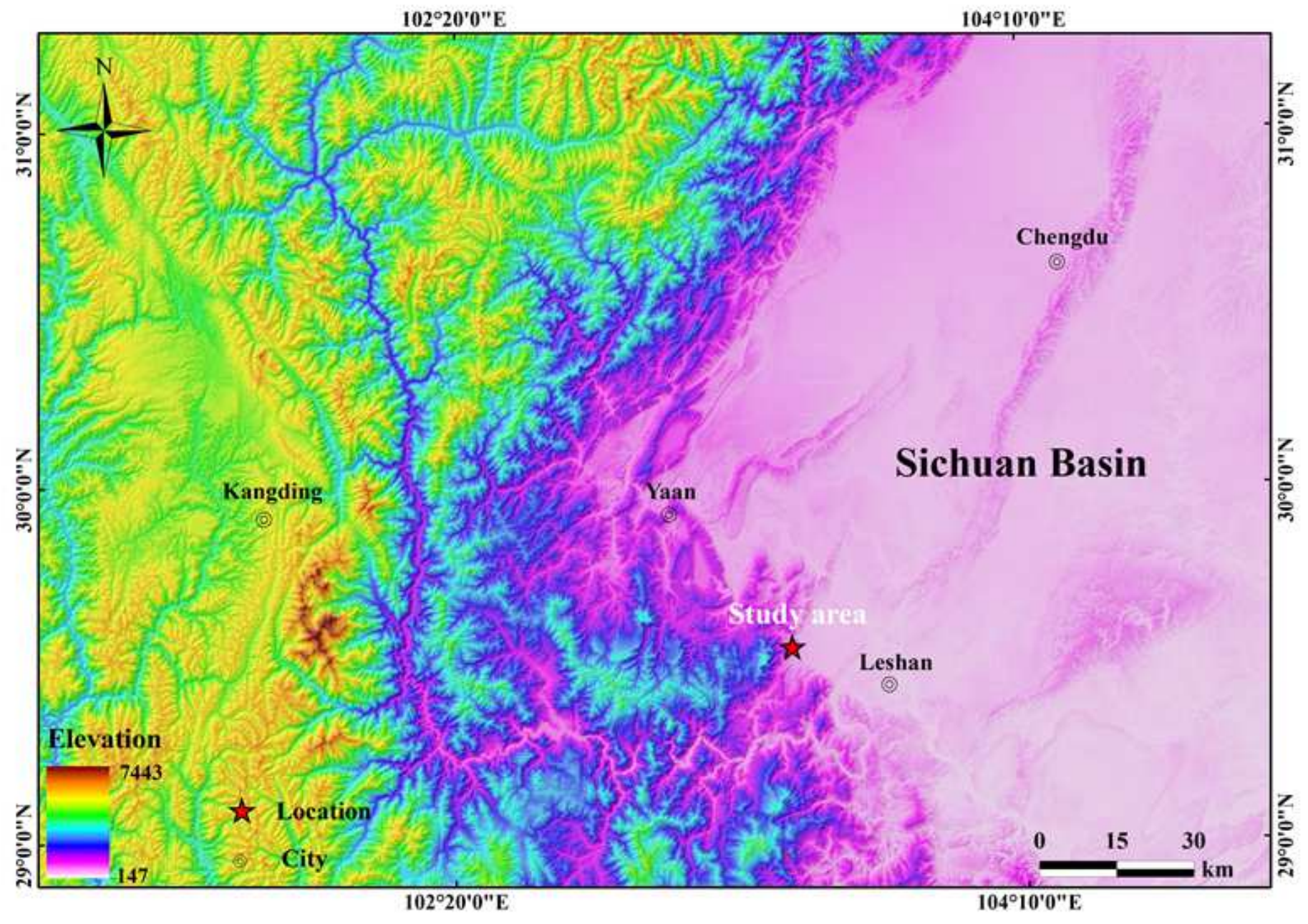

Figure 2

Location of the study area. Note: The designations employed and the presentation of the material on this map do not imply the expression of any opinion whatsoever on the part of Research Square concerning the legal status of any country, territory, city or area or of its authorities, or concerning the delimitation of its frontiers or boundaries. This map has been provided by the authors. 


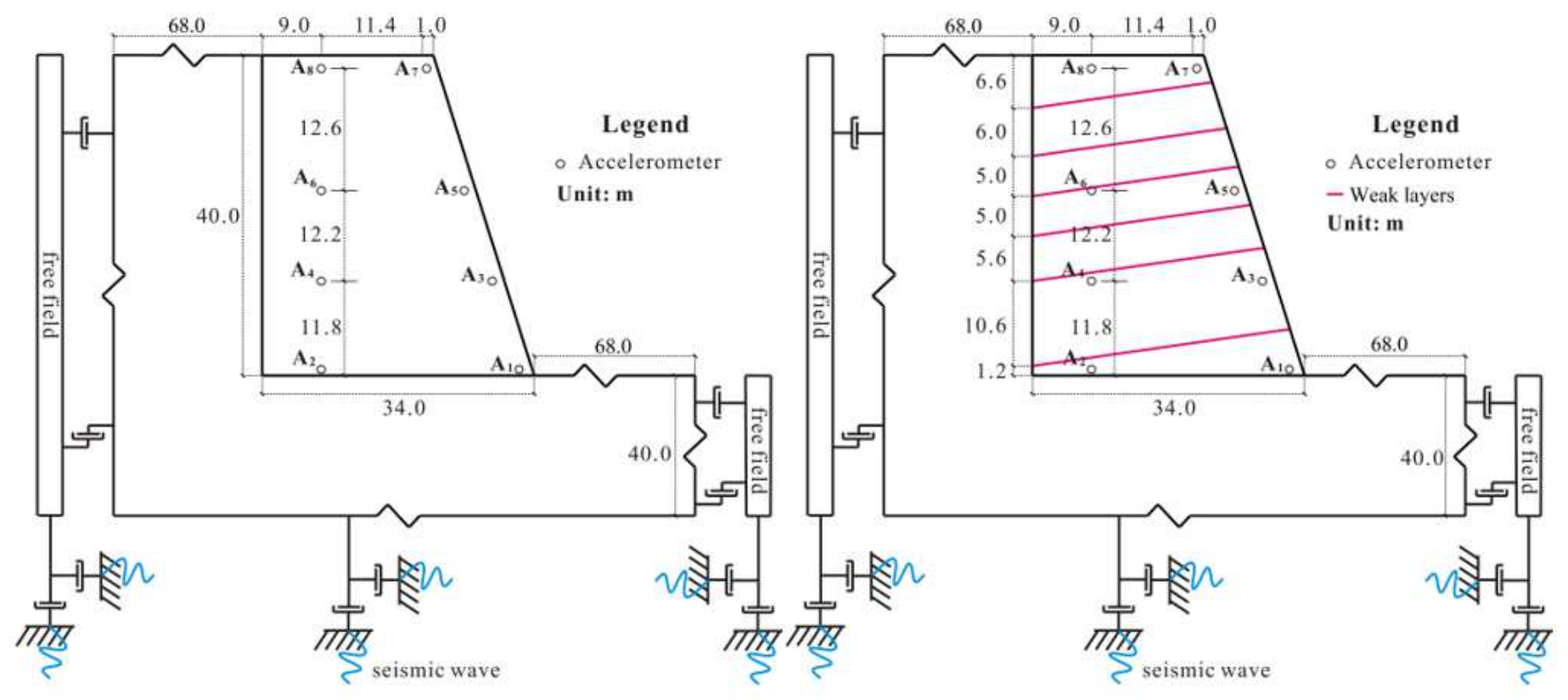

(a)

(b)

\section{Figure 3}

Boundary condition setting and layout of the monitoring points in the models: (a) homogeneous slope (Model 1); (b) toppling slope (Model 2).

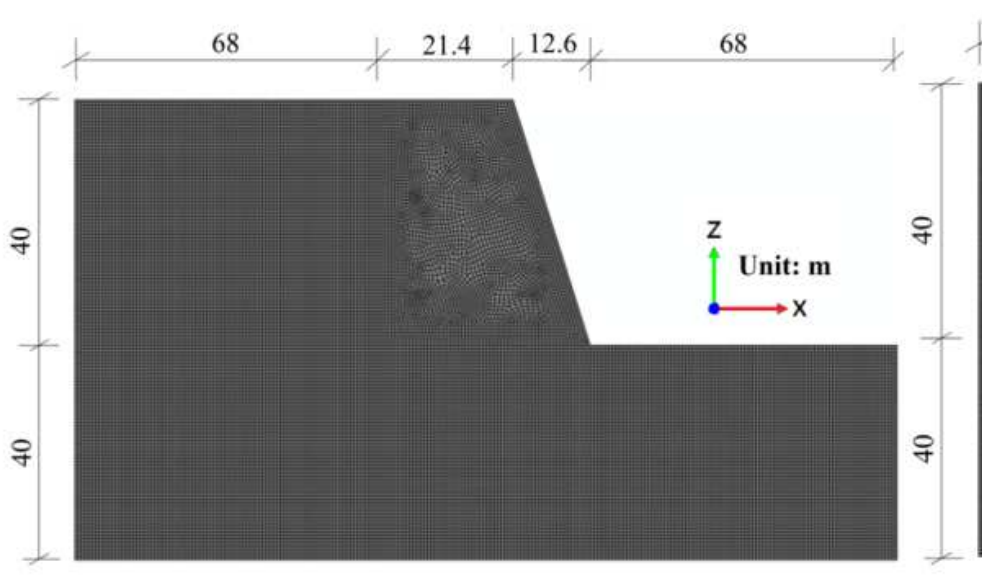

(a)

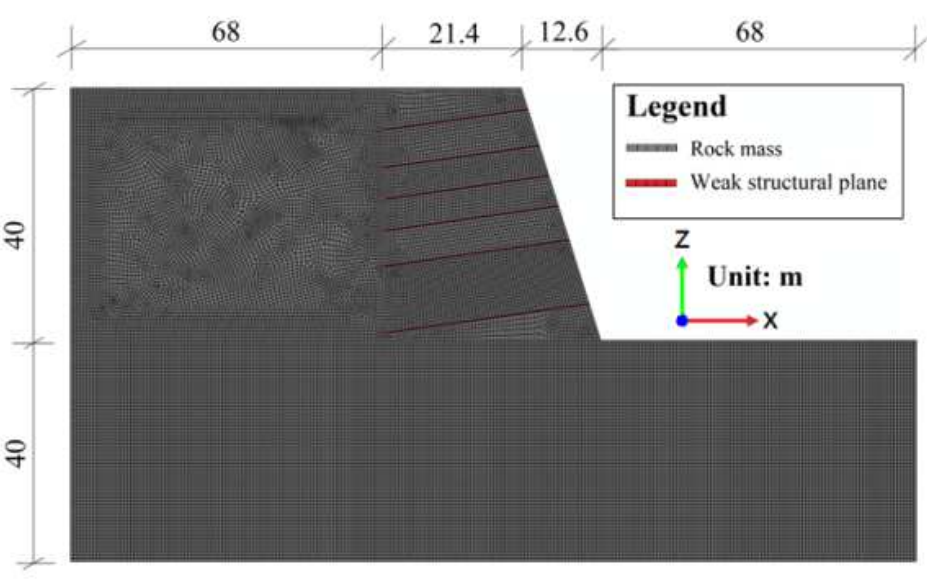

(b)

\section{Figure 4}

Mesh model of the rock mass slopes: (a) homogeneous slope (Model 1); (b) toppling slope (Model 2). 


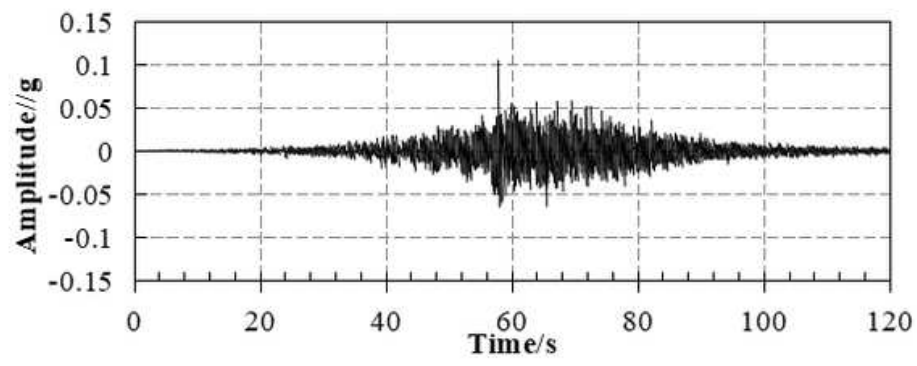

(a)

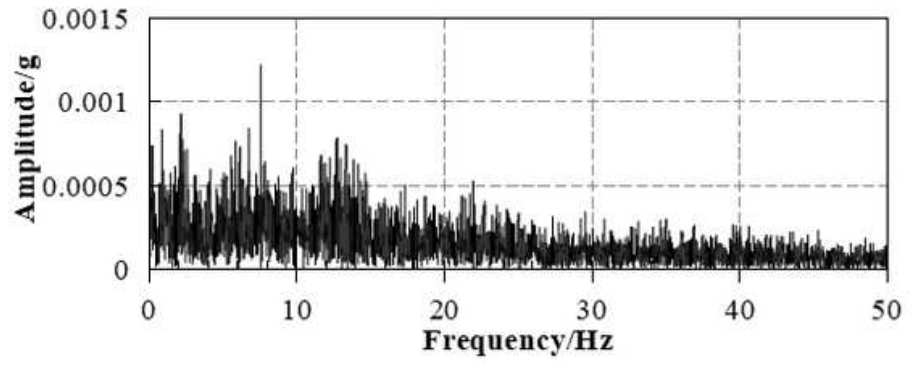

(b)

\section{Figure 5}

The input WE wave $(0.1 \mathrm{~g})$ : (a) Time history; (b) Fourier spectrum.

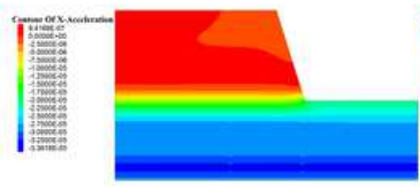

$t=0.02 \mathrm{~s}$

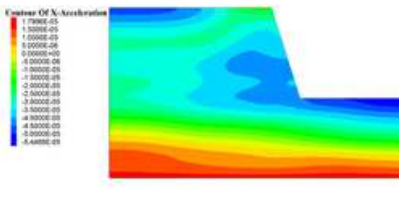

$t=0.04 \mathrm{~s}$

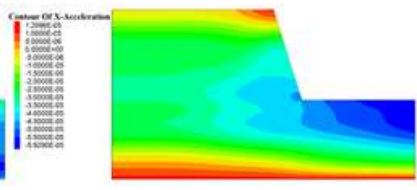

$t=0.03 \mathrm{~s}$

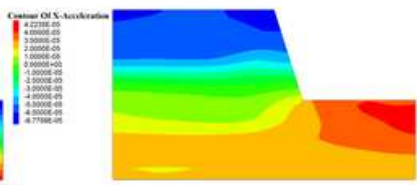

$t=0.05 s$

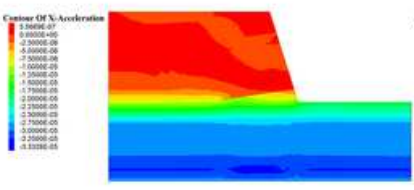

$\mathrm{t}=0.02 \mathrm{~s}$

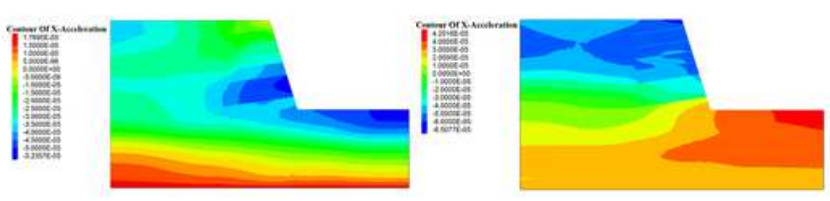

$t=0.04 \mathrm{~s}$

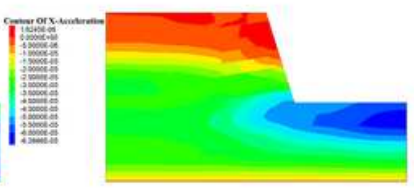

$\mathrm{t}=0.03 \mathrm{~s}$

(a)

(b)

Figure 6

Wave propagation characteristics through the slopes when input WE wave in $x$ direction: (a) homogeneous slope; (b) toppling slope (Unit: m/s2). 

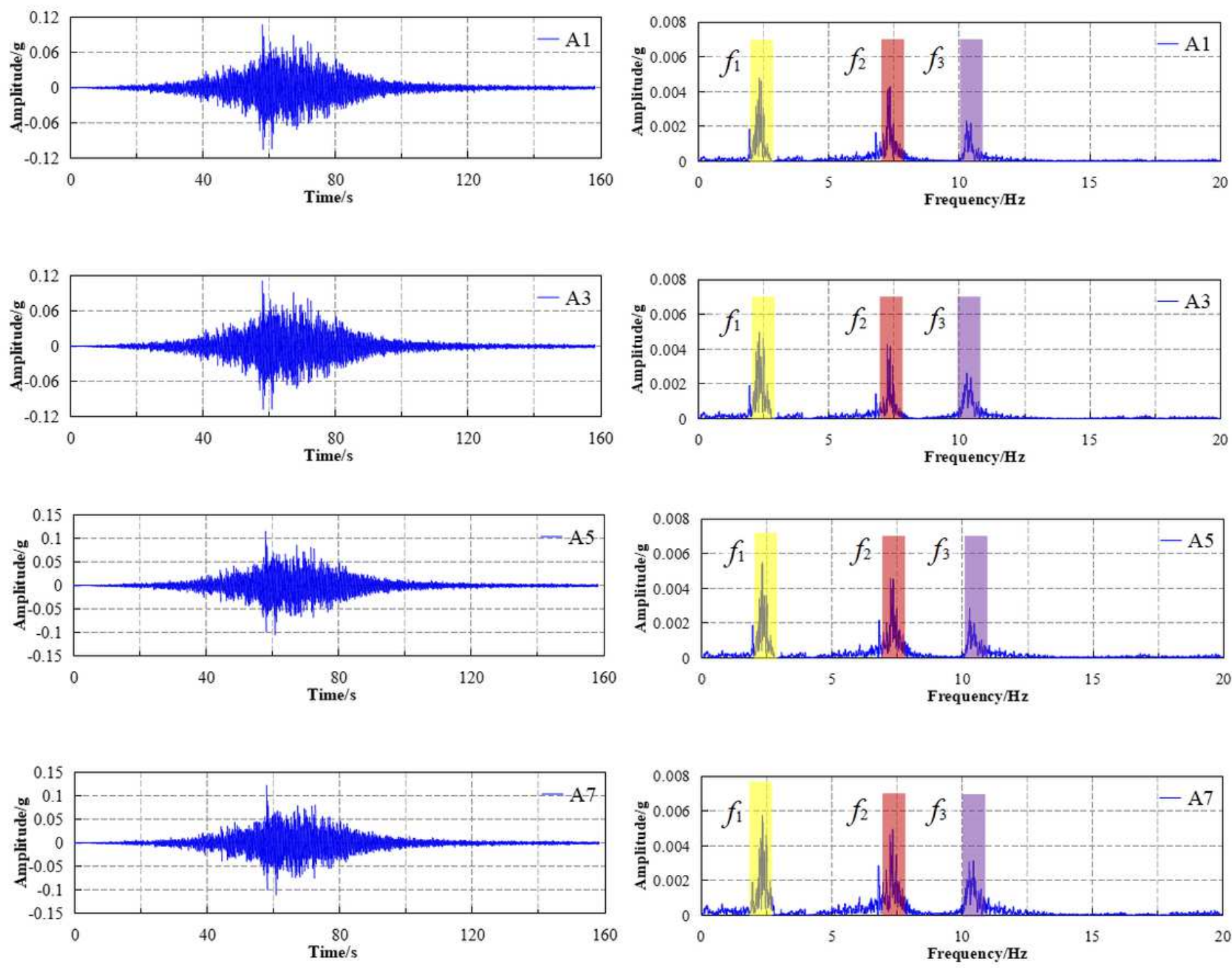

Acceleration-time histories

Fourier spectrum

Figure 7

Acceleration time history and Fourier spectrum of the measuring points at the slope surface (Model 1). 

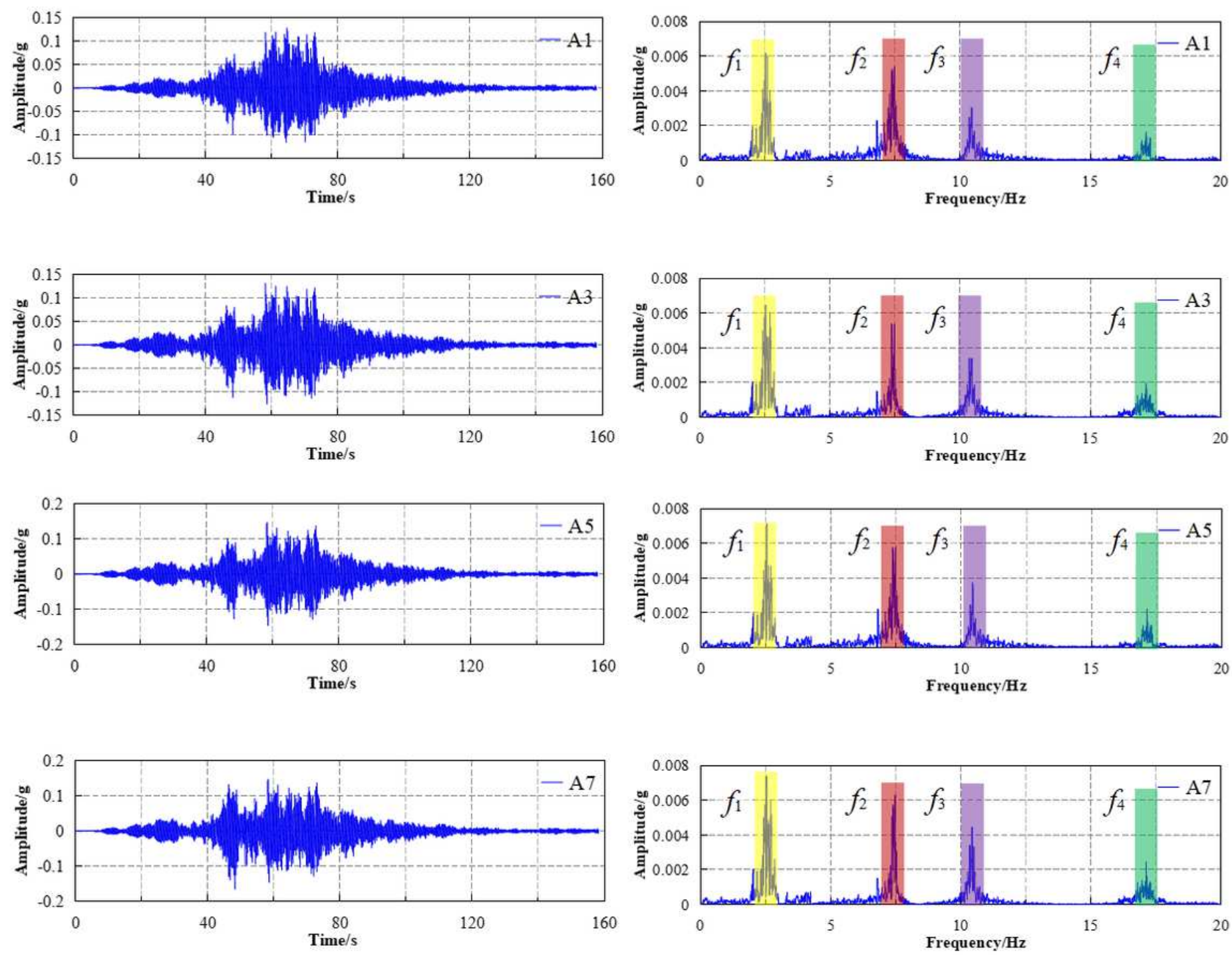

Acceleration-time histories

Fourier spectrum

Figure 8

Acceleration time history and Fourier spectrum of the measuring points at the slope surface (Model 2). 


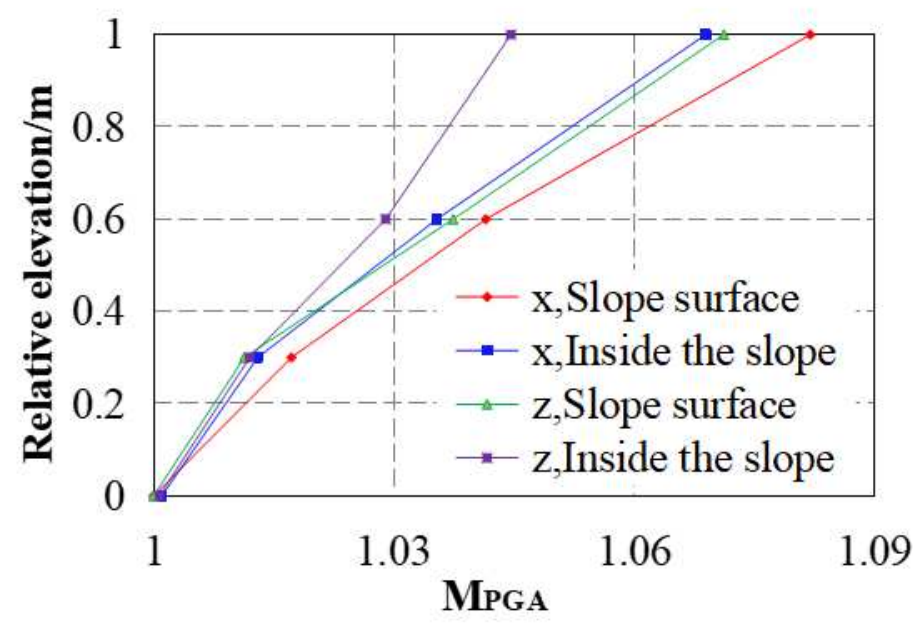

(a)

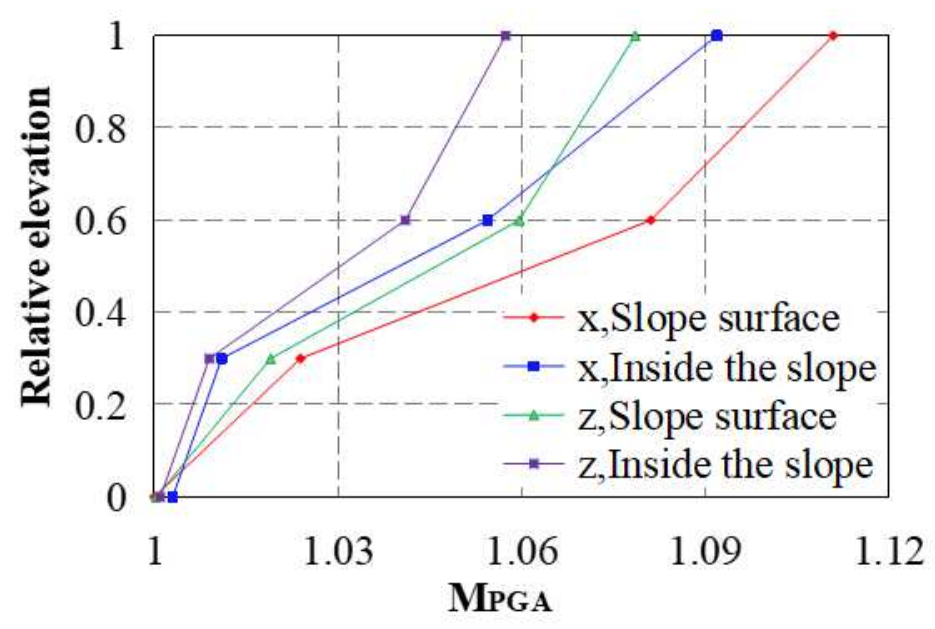

(b)

Figure 9

MPGA change rule of the slope when input WE wave $(0.1 \mathrm{~g})$ : (a) Model 1; (b) Model 2.

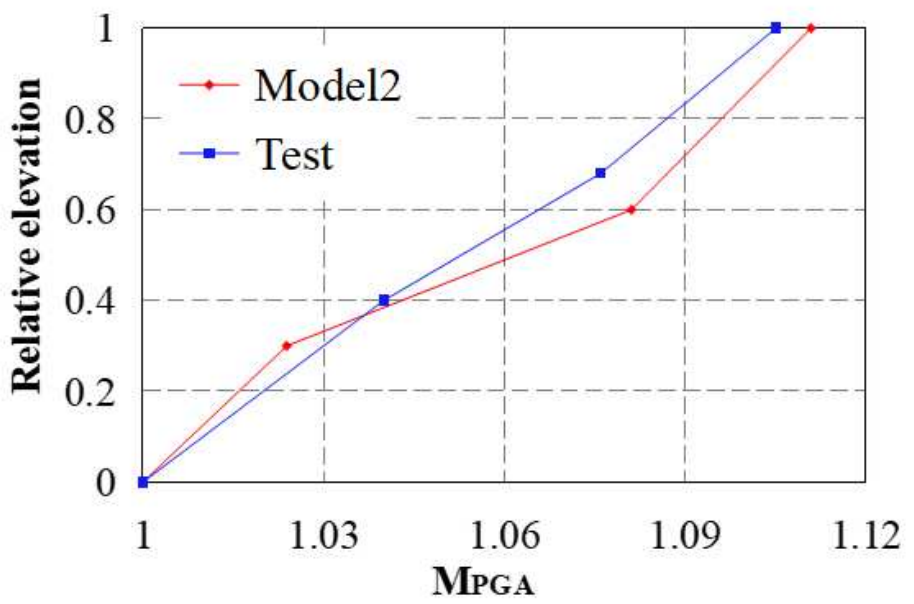

(a)

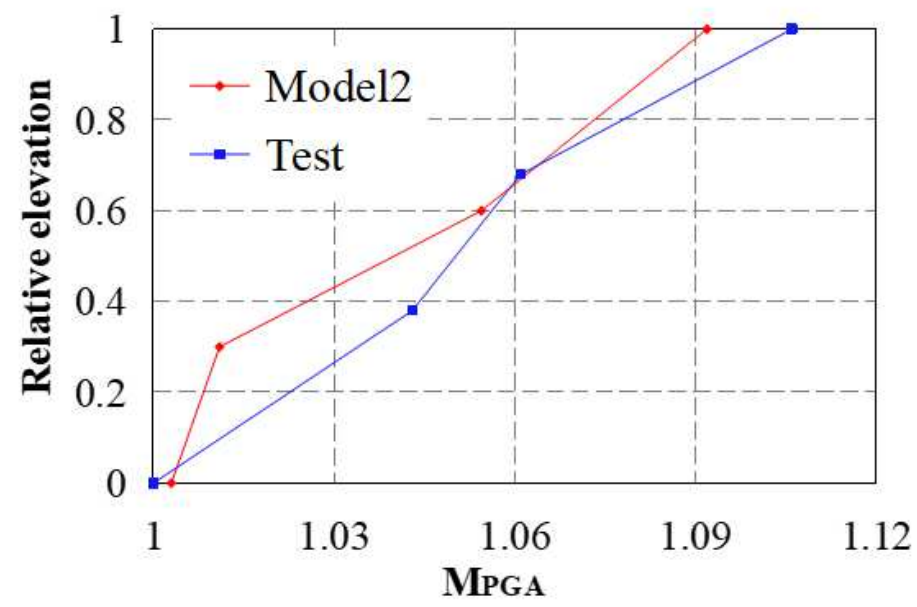

(b)

\section{Figure 10}

MPGA change rule of the toppling slope when input WE wave in $x$ direction $(0.1 \mathrm{~g})$ : (a) Inside the slope; (b) naear the slope surface. 


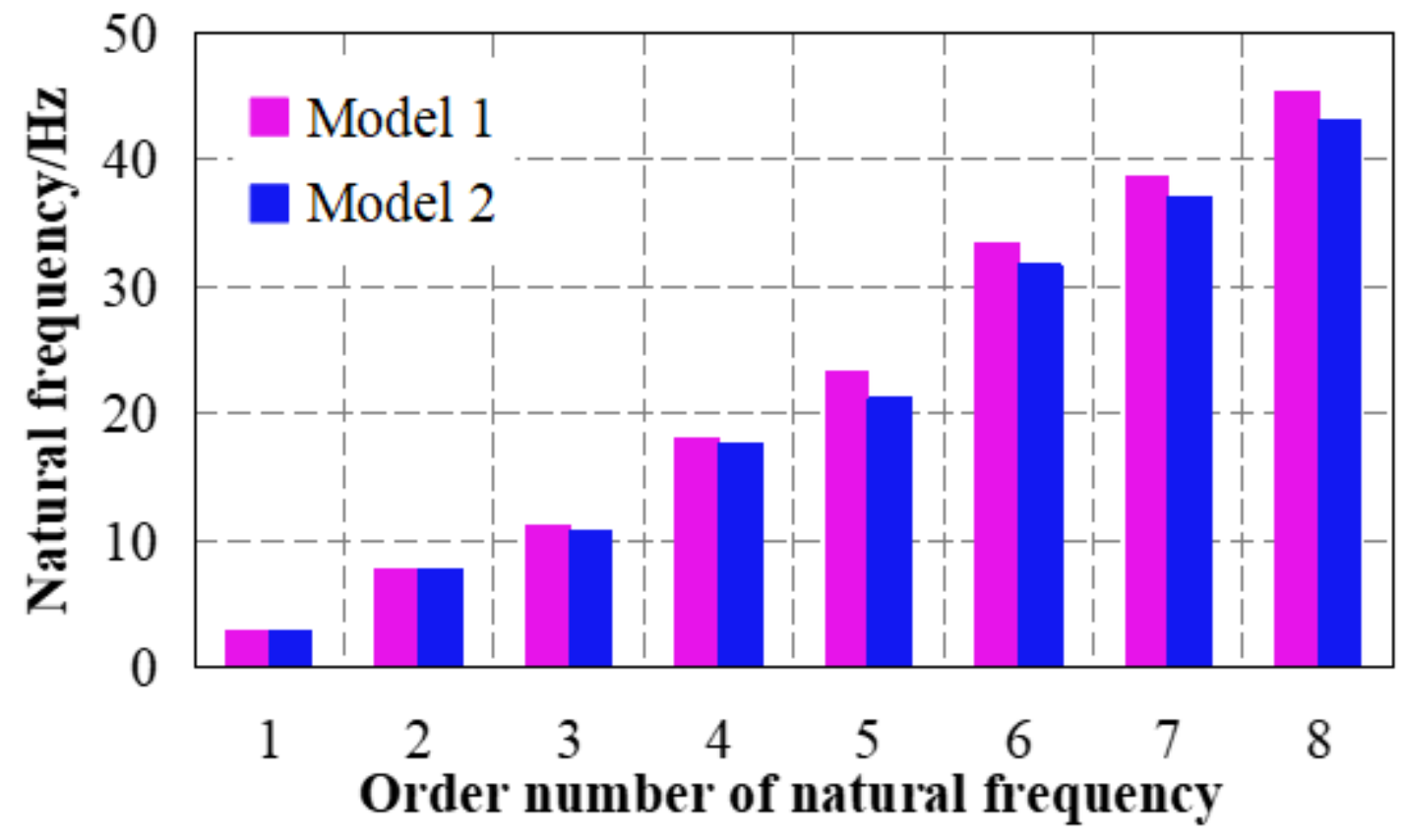

Figure 11

Natural frequency of the slope according to modal analysis by using FEM. 


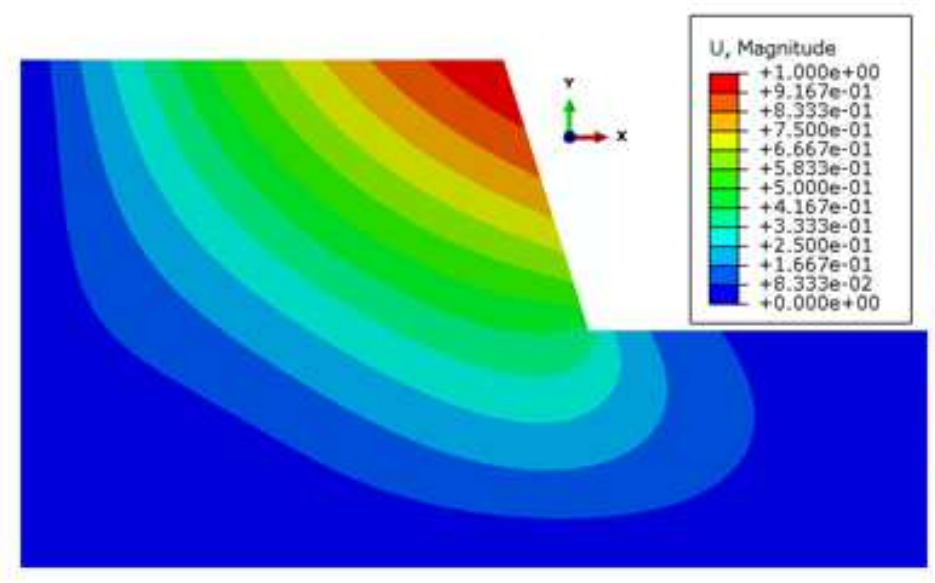

(a)

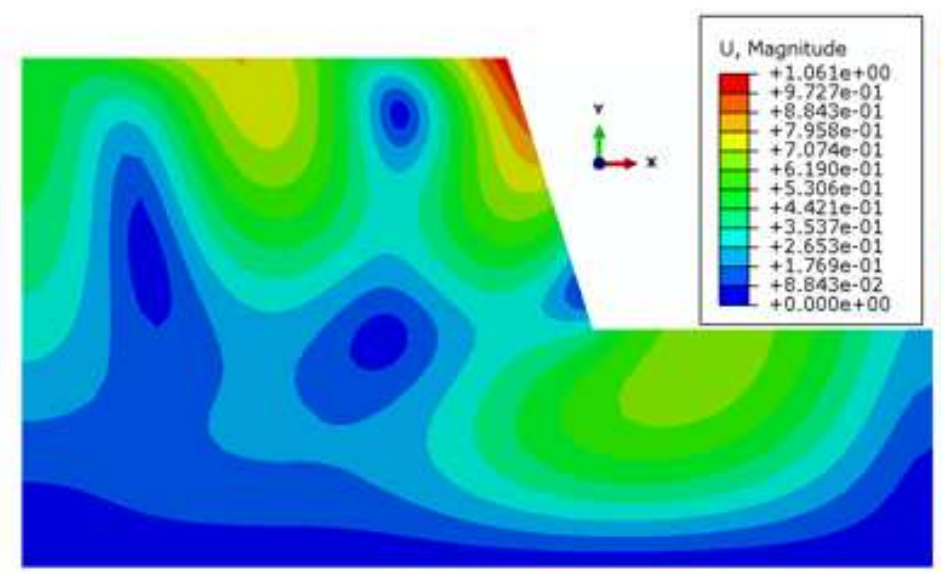

(c)

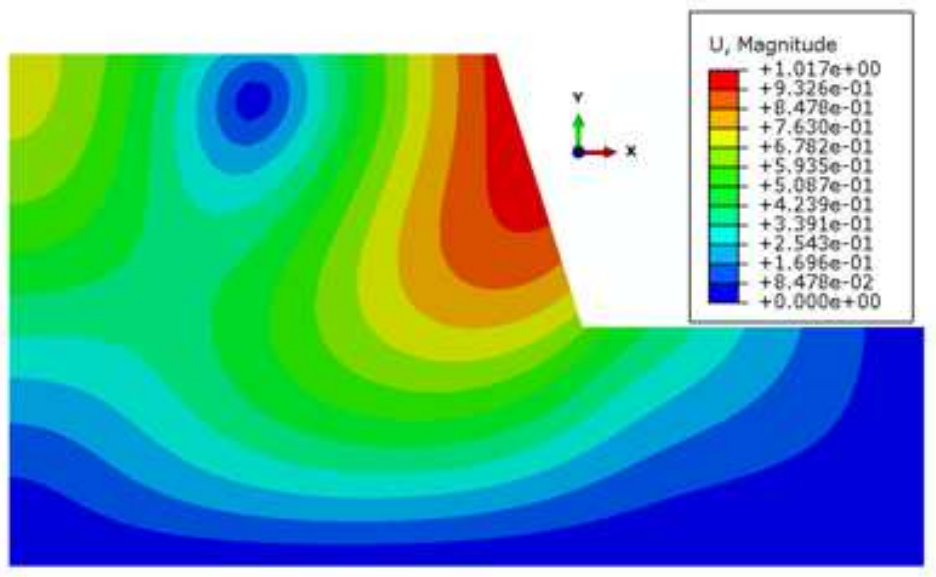

(b)

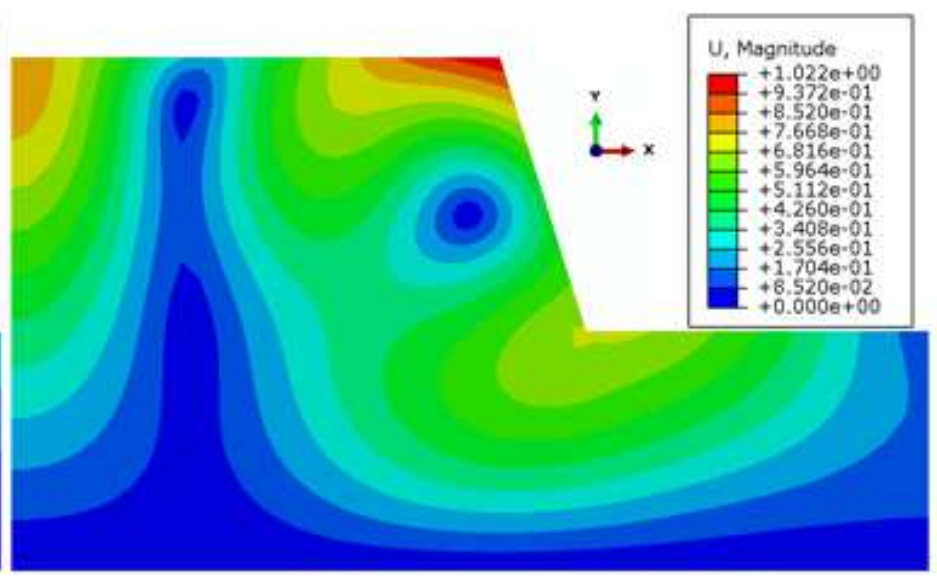

(d)

Figure 12

Results of modal analysis of the homogeneous slope: (a) Mode $1(2.96 \mathrm{~Hz}) ;$ (b) Mode $2(7.84 \mathrm{~Hz})$; (c) Mode $3(11.18 \mathrm{~Hz})$; (d) Mode $4(18.06 \mathrm{~Hz})$. 

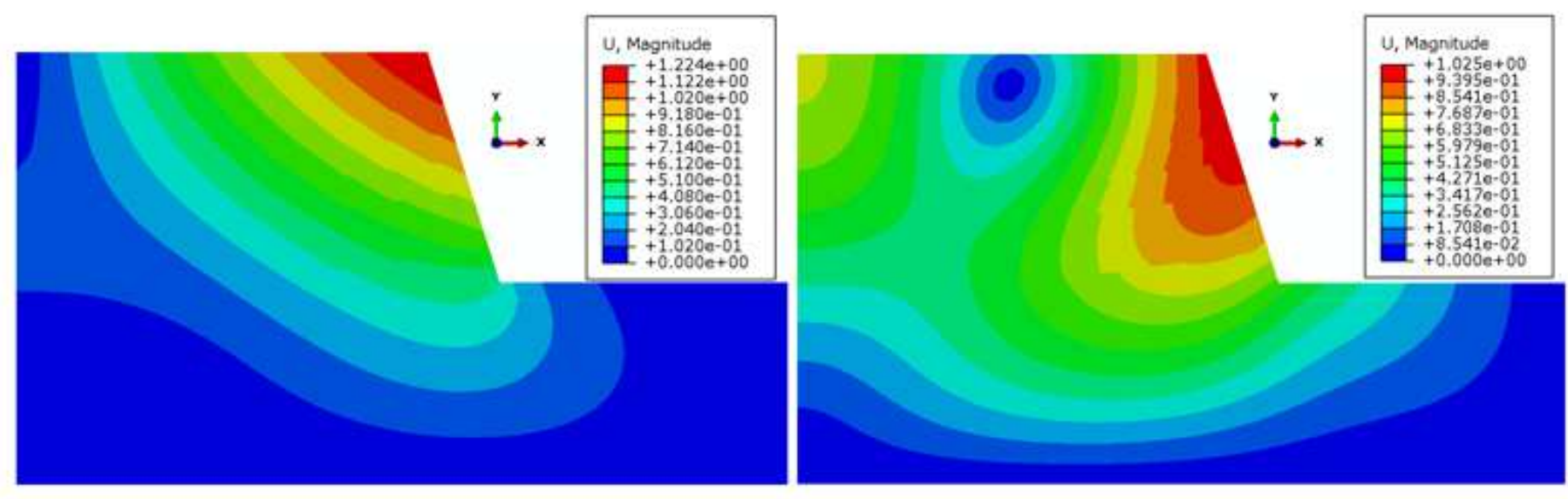

(a)

(b)
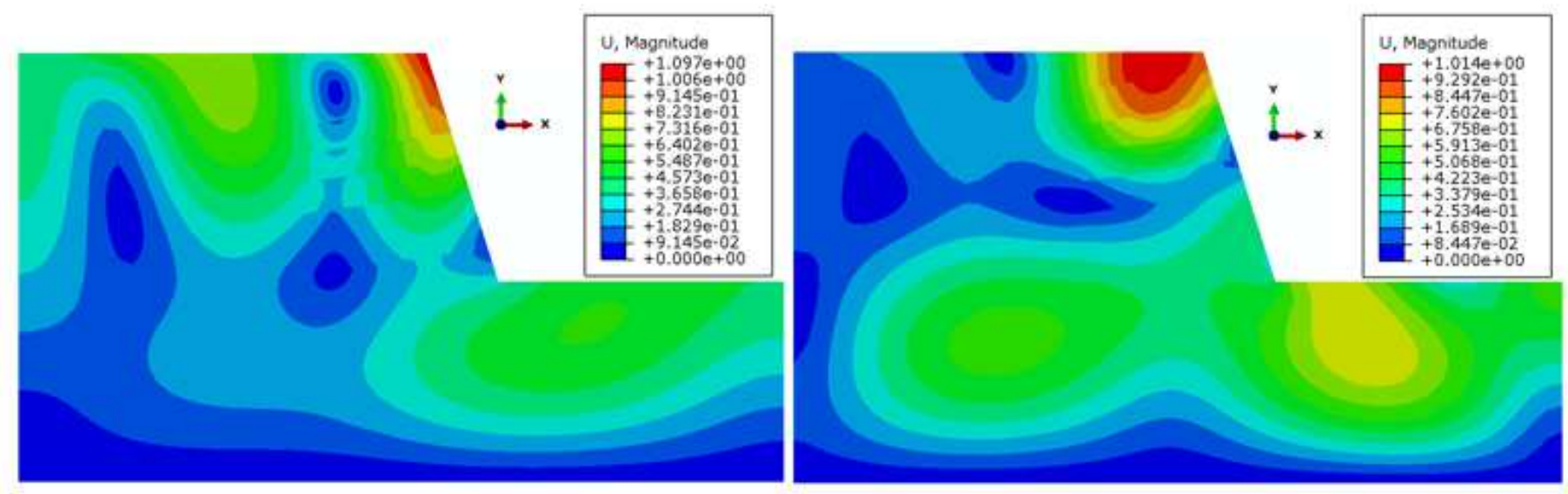

(c)

(d)

\section{Figure 13}

Results of modal analysis of the toppling slope: (a) Mode $1(2.81 \mathrm{~Hz})$; (b) Mode 2 (7.34 Hz); (c) Mode 3 (10.69 Hz); (d) Mode 4 (17.63 Hz). 


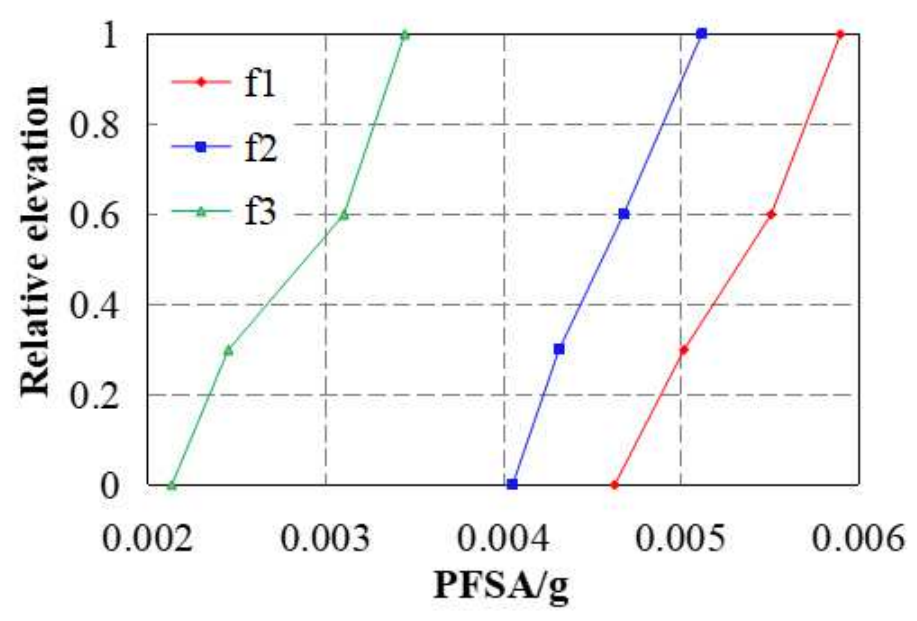

(a)

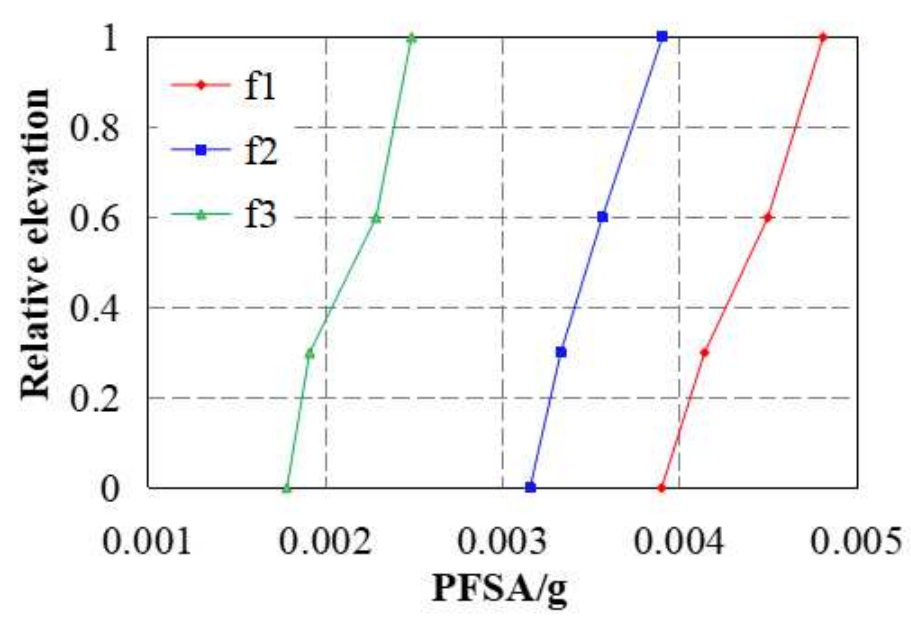

(b)

\section{Figure 14}

The PFSA change rule of the homogeneous slope when input WE wave in $x$ direction: (a) at the slope surface; (b) inside the slope.

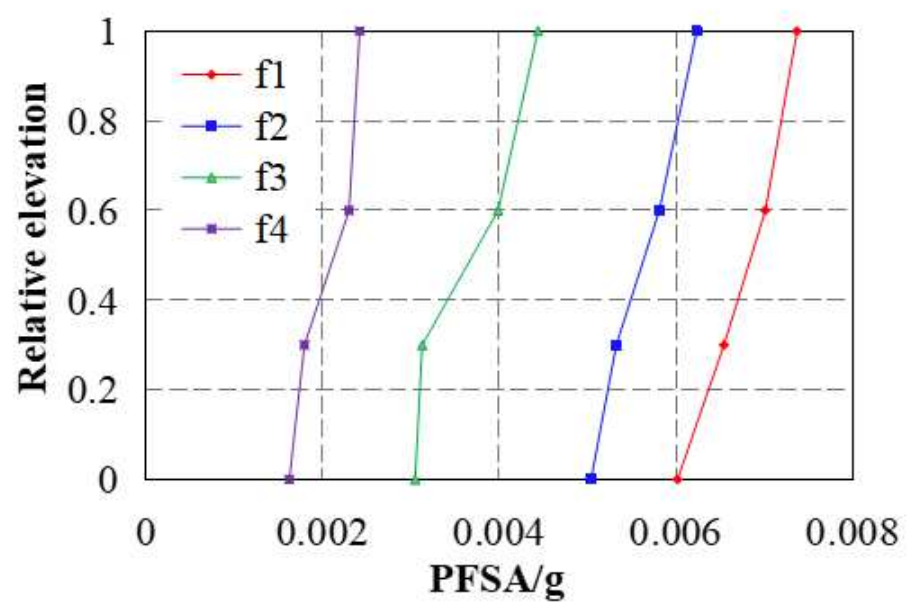

(a)

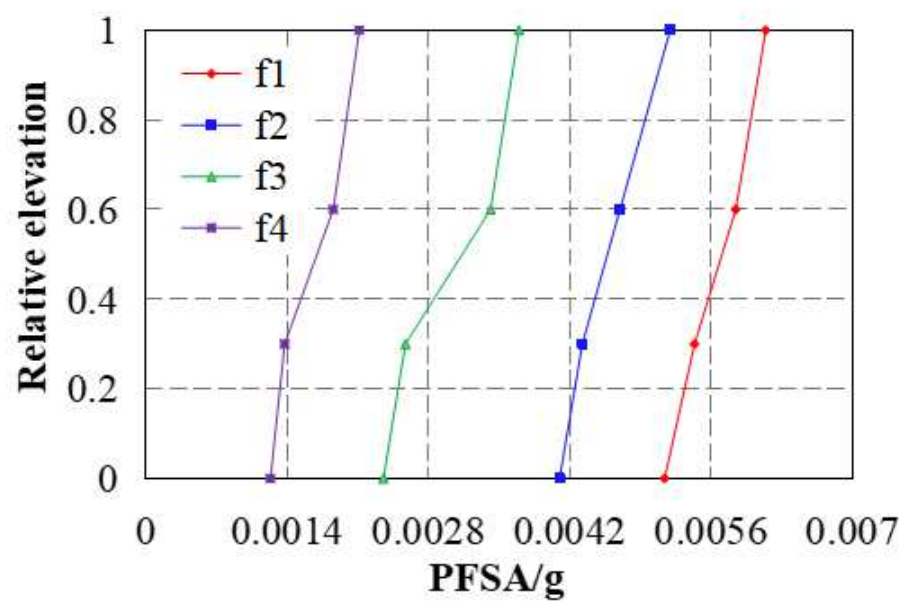

(b)

\section{Figure 15}

The PFSA change rule of the toppling slope when input WE wave in $x$ direction: (a) at the slope surface; (b) inside the slope. 


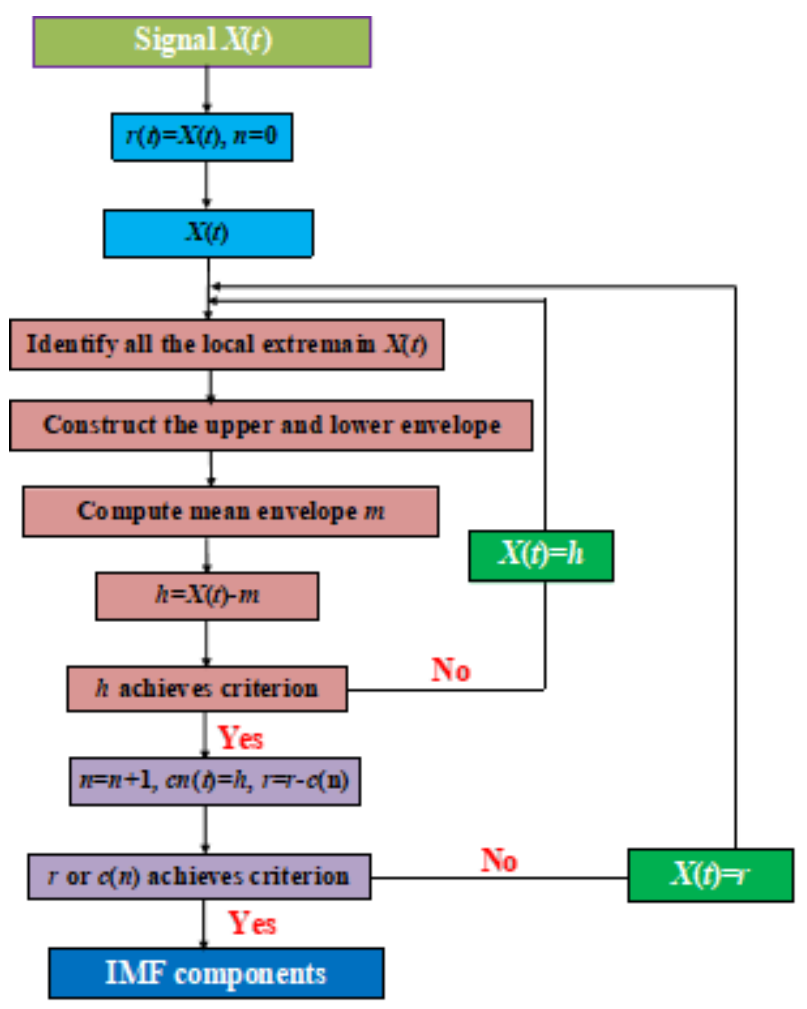

Figure 16

Flowchart for EMD approach (Zhang 2006). 

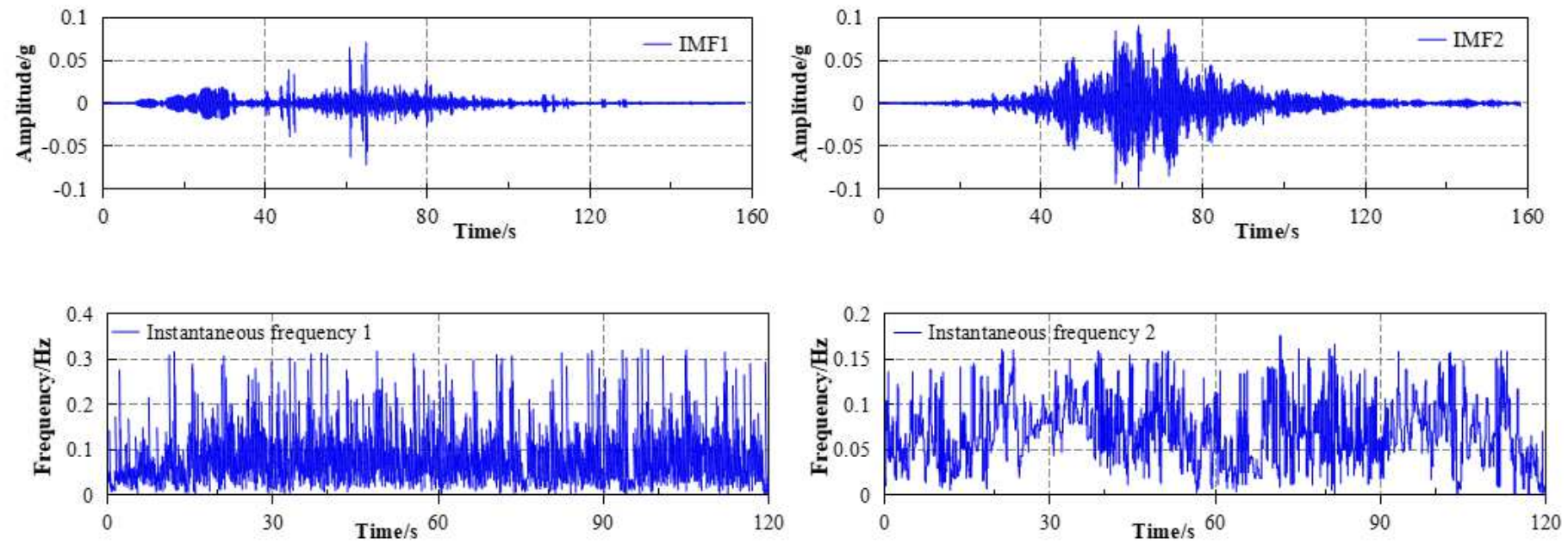

(a)

(b)
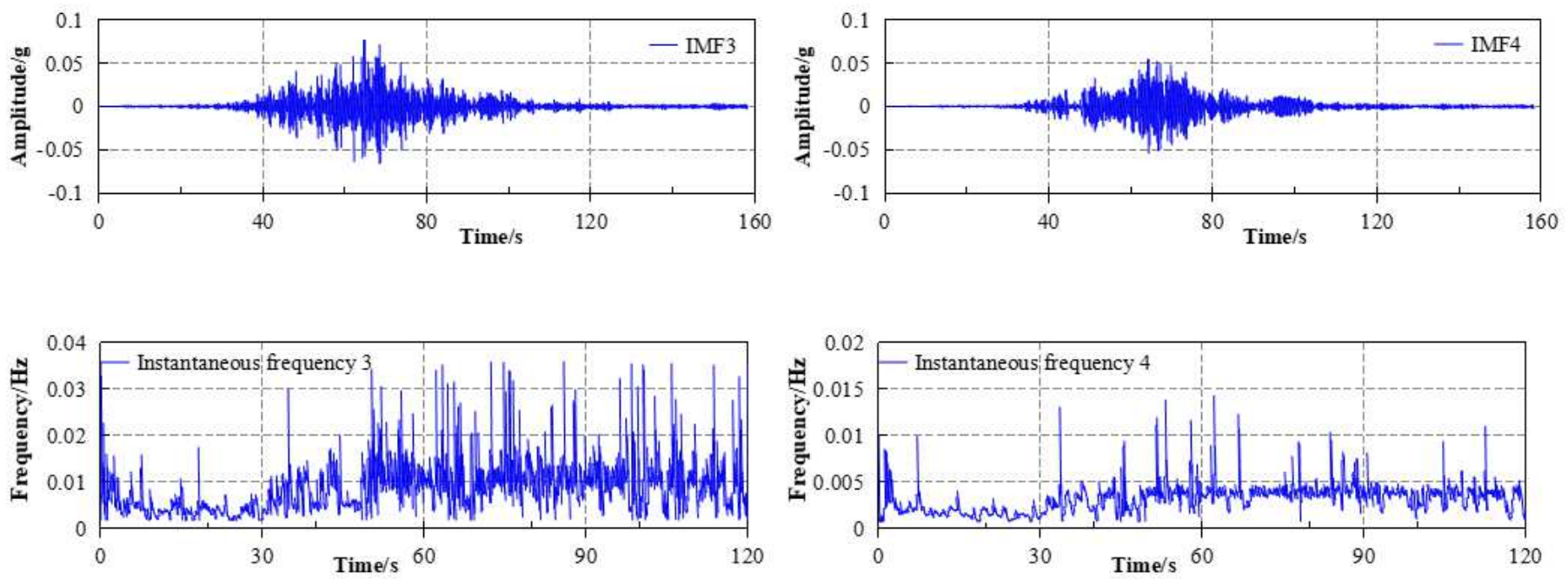

(c)

(d)

Figure 17

EMD results of the acceleration time history of point A1 when input in WE wave (0.1 g): (a) IMF1, (b) IMF2, (c) IMF3 and (d) IMF4. 

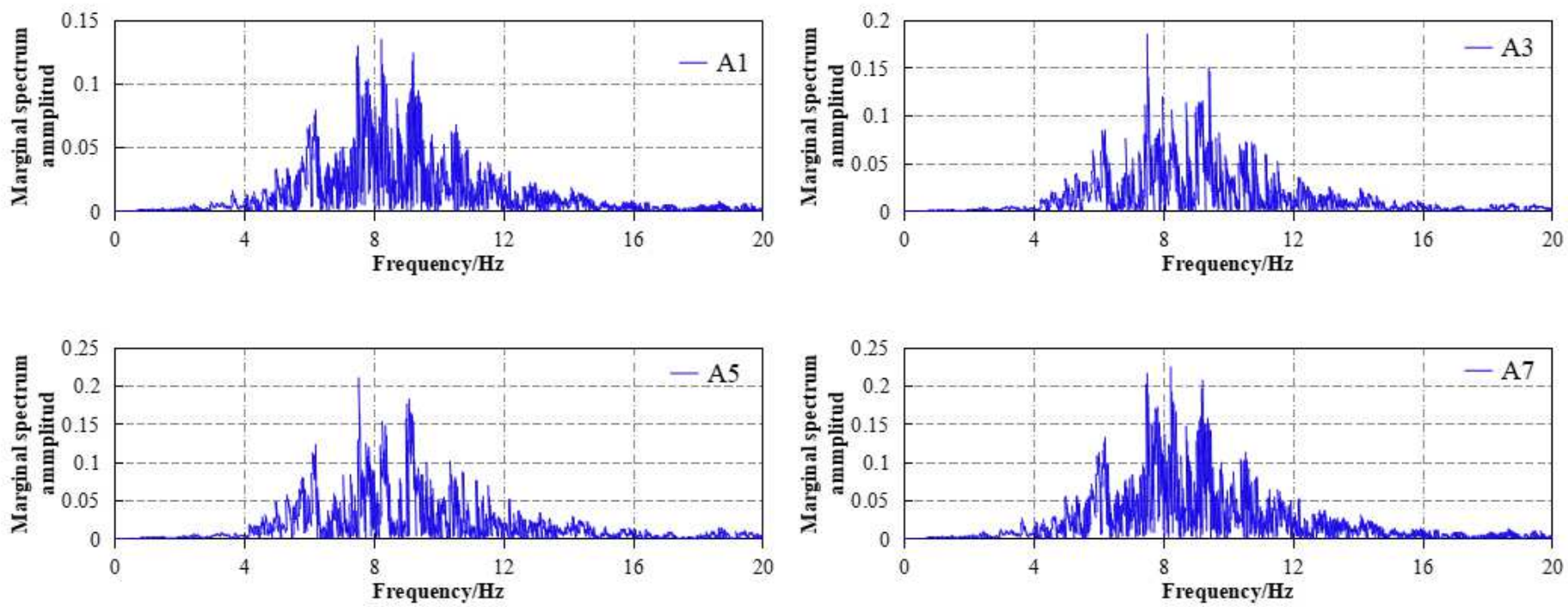

Figure 18

The marginal spectrum amplitude of the points near the slope surface when input WE wave in $\mathrm{x}$ direction $(0.1 \mathrm{~g})$.

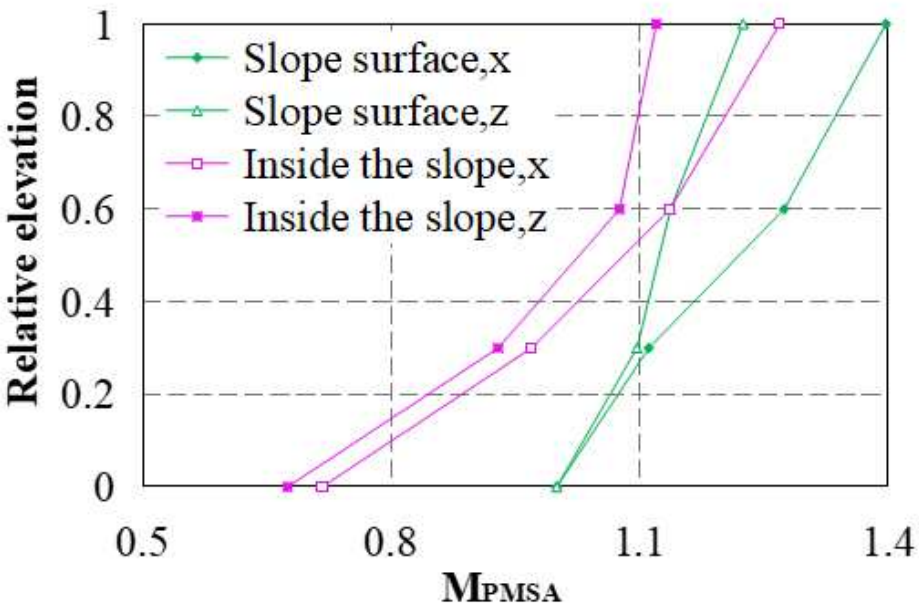

(a)

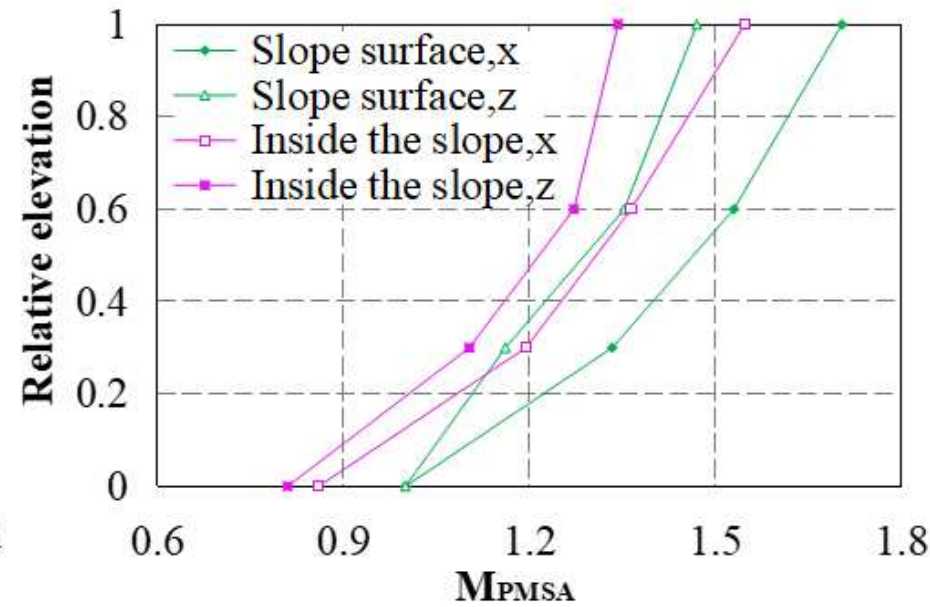

(b)

\section{Figure 19}

The change rule of PMSA with elevation of the toppling slope when input WE wave: (a) homogeneous slope; (b) toppling slope. 


\section{Contour of XX-Stress}

Calculated by: Volumetric Averaging

$3.4600 \mathrm{E}+04$

$2.5000 \mathrm{E}+04$

$0.0000 E+00$

$-2.5000 E+04$

$-5.0000 E+04$

$-7.5000 E+04$

$-1.0000 E+05$

$-1.2500 E+05$

$-1.5000 \mathrm{E}+05$

$-1.7500 E+05$

$-2.0000 E+05$

$-2.2500 E+05$

$-2.4707 E+05$

\section{Figure 20}

Stress distribution of the bedding slopes when input in $\mathrm{x}$ direction $(0.1 \mathrm{~g})$.
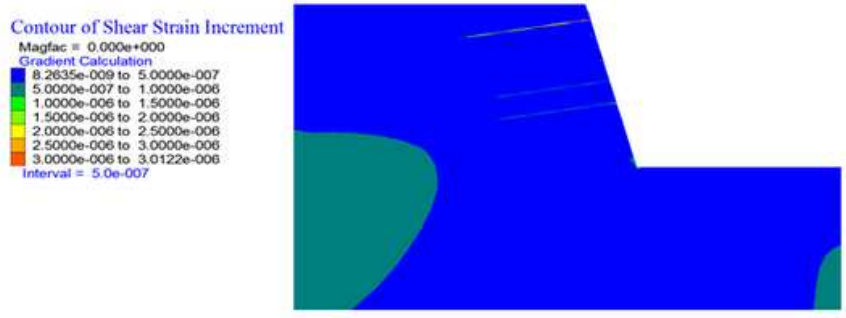

(a)

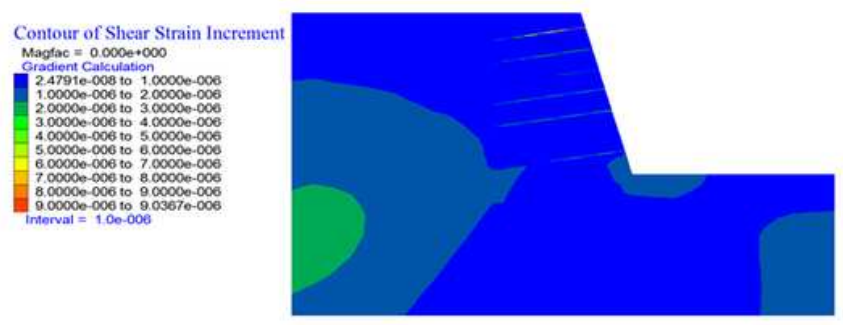

(b)
Contour of Shear Strain Increment Magtac $=0.0000+000$
Gradient Calculatar

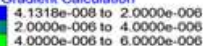

$600000-006$ to 8.000000000

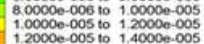

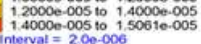

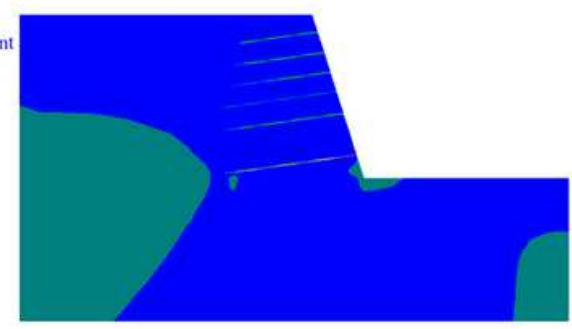

(c)

Contour of Shear Strain Incremen Magtac $=0.0000+000$

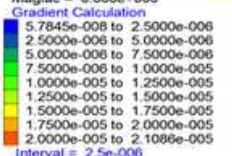

200000 -005 to $20.000000-005$

\section{Figure 21}


Contours of shear strain increment in the weak zone when input WE wave in $x$ direction: (a) $0.1 \mathrm{~g}$; (b) 0.3 g; (c) $0.4 \mathrm{~g}$; (d) $0.6 \mathrm{~g}$.

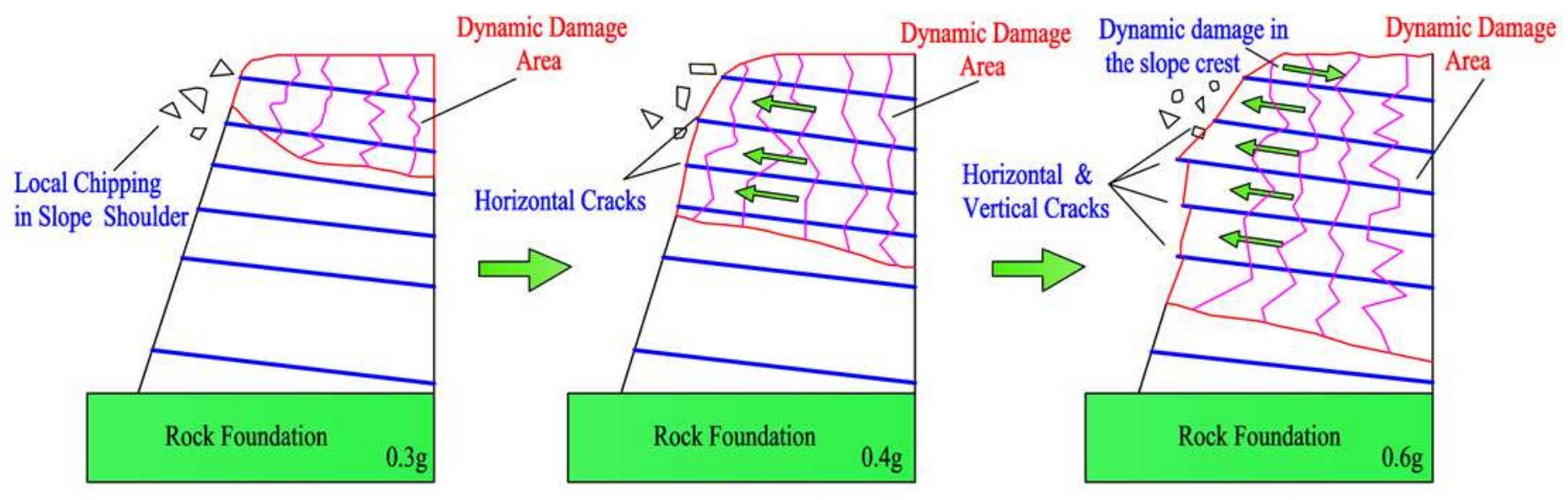

Figure 22

Failure process of the toppling slope during shaking table tests (Fan et al. 2016). 